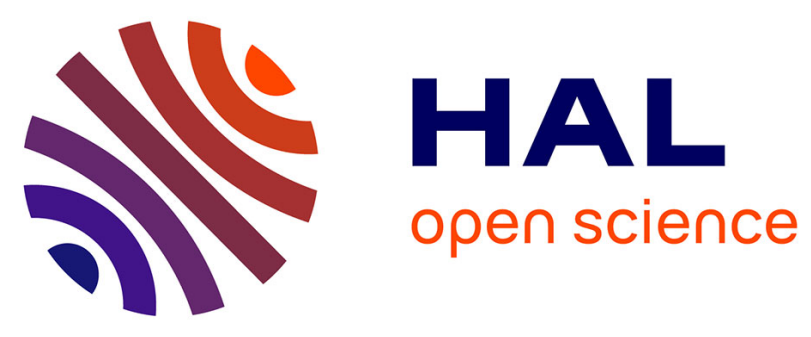

\title{
Twins - A weak link in the magnetic hardening of ThMn12-type permanent magnets
}

Semih Ener, Konstantin P Skokov, Dhanalakshmi Palanisamy, Thibaut

Devillers, Johann Fischbacher, Gabriel Gomez Eslava, Fernando Maccari, Lukas Schäfer, Léopold V.B. Diop, Iliya Radulov, et al.

\section{To cite this version:}

Semih Ener, Konstantin P Skokov, Dhanalakshmi Palanisamy, Thibaut Devillers, Johann Fischbacher, et al.. Twins - A weak link in the magnetic hardening of ThMn12-type permanent magnets. Acta Materialia, 2021, 214, pp.116968. 10.1016/j.actamat.2021.116968 . hal-03325734

\section{HAL Id: hal-03325734 \\ https://hal.science/hal-03325734}

Submitted on 25 Aug 2021

HAL is a multi-disciplinary open access archive for the deposit and dissemination of scientific research documents, whether they are published or not. The documents may come from teaching and research institutions in France or abroad, or from public or private research centers.
L'archive ouverte pluridisciplinaire HAL, est destinée au dépôt et à la diffusion de documents scientifiques de niveau recherche, publiés ou non, émanant des établissements d'enseignement et de recherche français ou étrangers, des laboratoires publics ou privés. 


\section{Twins - A weak link in the magnetic hardening of ThMn12-type permanent magnets}

Semih Ener ${ }^{1}$,*, Konstantin P. Skokov ${ }^{1}$, Dhanalakshmi Palanisamy ${ }^{2}$, Thibaut Devillers ${ }^{3}$, Johann Fischbacher ${ }^{4}$, Gabriel Gomez Eslava ${ }^{3}$, Fernando Maccari ${ }^{1}$, Lukas Schäfer ${ }^{1}$, Léopold V. B.

Diop ${ }^{1}$, Iliya Radulov ${ }^{1}$, Baptiste Gault ${ }^{2,5}$, Gino Hrkac ${ }^{6}$, Nora M. Dempsey ${ }^{3}$, Thomas Schrefl ${ }^{4}$, Dierk Raabe ${ }^{2}$ and Oliver Gutfleisch ${ }^{1}$

${ }^{1}$ Functional Materials, Department of Material Science, Technical University of Darmstadt, Darmstadt, 64287, Germany

${ }^{2}$ Max-Planck-Institute für Eisenforschung GmbH, Düsseldorf, 40237 Germany

${ }^{3}$ Univ. Grenoble Alpes, CNRS, Institut NEEL, Grenoble, 38000 France

${ }^{4}$ Department for Integrated Sensor Systems, Danube University Krems, Krems 3500, Austria

${ }^{5}$ Department of Materials, Royal School of Mines, Imperial College London, London, SW7 2AZ, United Kingdom

${ }^{6}$ College of Engineering, Mathematics and Physical Sciences, University of Exeter, North Park Road, Exeter EX4 4QF, United Kingdom

E-mail: semih.ener@tu-darmstadt.de

$\mathrm{Nd}_{2} \mathrm{Fe}_{14} \mathrm{~B}$-type materials exhibit the highest energy product around room temperature and hence dominate the high-performance permanent magnet market. Intensive research efforts aim at alternative material systems containing less critical elements with similar or better magnetic properties. Nd- and Sm-based compounds with a $\mathrm{ThMn}_{12}$-type structure exhibit intrinsic properties comparable or even superior to $\mathrm{Nd}_{2} \mathrm{Fe}_{14} \mathrm{~B}$. However, it has not been possible to achieve technically relevant coercivity and remanent magnetization in $\mathrm{ThMn}_{12}$-based bulk sintered magnets. Using $\mathrm{SmFe}_{11} \mathrm{Ti}$ as a prototypical representative, we demonstrate that one important reason for the poor performance is the formation of twins inside micro-crystalline grains. The nature of the twins in $\mathrm{SmFe}_{11} \mathrm{Ti}$ was investigated in twinned "single crystals" and both bulk and thin film poly-crystalline samples, using advanced electron microscopy and atom probe tomography as well as simulations and compared with benchmark $\mathrm{Nd}_{2} \mathrm{Fe}_{14} \mathrm{~B}$. Both micro-twins and nano-twins show a twin orientation of $57 \pm 2^{\circ}$ and an enrichment in Sm, which could affect domain wall motion in this 
material. Micromagnetic simulations indicate that twins act as nucleation centers, representing the magnetically weakest link in the microstructure. The relation between twin formation energies and geometrical features are briefly discussed using molecular dynamic simulations.

Keywords: magnets, ThMn ${ }_{12}$-type compounds, coercivity, twin boundaries, microstructure

\section{Introduction}

$\mathrm{Nd}_{2} \mathrm{Fe}_{14} \mathrm{~B}$-type magnets are key components in electro-mobility, wind turbines, robotics and automatization with expected strong increases in demand in all sectors. The rare-earth (RE) supply crisis of ten years ago led to a drastic increase in prices and revealed the dependency on critical RE elements [1] for the production of high performance permanent magnets. Significant efforts are ongoing to find alternative material systems which present magnetic properties similar or superior to those the $\mathrm{Nd}_{2} \mathrm{Fe}_{14} \mathrm{~B}$ benchmark, but which contain less critical elements [2].

RE-lean Nd- and Sm-based alloys with ThMn ${ }_{12}$-type structures (tetragonal I4/mmm \#139) have been known for more than 30 years. More recently, in 2015, Hirayama et al. reported the intrinsic magnetic properties of $\mathrm{NdFe}_{12} \mathrm{~N}_{x}$ thin films (saturation magnetization $\mu_{0} M_{s} \sim 1.66 \mathrm{~T}$, anisotropy field $\mu_{0} H_{a} \sim 8 \mathrm{~T}$ and Curie temperature $T_{\mathrm{c}} \sim 550{ }^{\circ} \mathrm{C}$ ) to be superior to those of $\mathrm{Nd}_{2} \mathrm{Fe}_{14} \mathrm{~B}[3,4]$. However, the $\mathrm{ThMn}_{12}$-type structure was preserved only in thin-films with thicknesses up to 360 nm. A major drawback of the $\mathrm{NdFe}_{12} \mathrm{~N}_{x}$ system is the necessity of interstitial modification by nitrogen to obtain high saturation magnetization, anisotropy field and $T_{c}$. Decomposition of the nitride starting from around $570^{\circ} \mathrm{C}$ prevents conventional densification via sintering or hot pressing. Nonetheless, investigations of materials with the $\mathrm{Nd}(\mathrm{Fe}, \mathrm{X})_{12}$-composition show the 
possibility to stabilize $\mathrm{ThMn}_{12}$ structure in the bulk state by addition of doping elements, such as $\mathrm{Cr}, \mathrm{V}, \mathrm{Ti}, \mathrm{Mo}, \mathrm{W}$ or $\mathrm{Si}[5,6]$, that substitute Fe atoms. Among these elements, Ti is very effective and stabilizes the structure with minimal doping (approx. 7.7 at.\%) [7].

The sign of the Stevens factor $\alpha_{\mathrm{J}}$ of $\mathrm{Sm}^{3+}$ is opposite to that of $\mathrm{Nd}^{3+}$, and as a consequence $\mathrm{Sm}(\mathrm{Fe}, \mathrm{Ti})_{12}$ exhibits a high anisotropy field $\left(\mu_{0} H_{A} \sim 10 \mathrm{~T}\right.$ at room temperature [8]) without any interstitial modification, which makes it a promising material for the production of anisotropic bulk and fully dense permanent magnets. In 2017, Hirayama et al. reported that the intrinsic magnetic properties of cobalt doped $\mathrm{Sm}\left(\mathrm{Fe}_{1-x} \mathrm{Co}_{x}\right)_{12}$ thin films are superior to those of $\mathrm{Nd}_{2} \mathrm{Fe}_{14} \mathrm{~B}$ [9]. Other studies showed that the addition of $\mathrm{Zr}$ reduces the Ti concentration required to stabilize the $\mathrm{ThMn}_{12^{-}}$ type structure in Sm-based bulk samples $[10,11]$. Zr substitution also leads to an increase in the saturation magnetization, but the anisotropy field decreases.

Even though the intrinsic magnetic properties of both $\mathrm{Nd}$ and Sm based ThMn 12 -type thin films are reported to be superior to those of $\mathrm{Nd}_{2} \mathrm{Fe}_{14} \mathrm{~B}$, the production of bulk $\mathrm{ThMn}_{12}$-type structures remains challenging [12-20]. The hardness parameter, defined as:

$\kappa=\sqrt{\frac{K_{1}}{\mu_{0} M_{s}^{2}}}$

quantitatively determines the probability of resisting self-demagnetization when hard magnetic materials are fabricated in any possible shape. An empirical rule of thumb to select materials as potential candidates for application as permanent magnet [21] is that $\kappa$ must be significantly greater than one. For $\mathrm{Nd}_{2} \mathrm{Fe}_{14} \mathrm{~B}$ the $\kappa$ value is 1.5 , while it rises to a value of 2.1 for $\mathrm{SmFe}_{11} \mathrm{Ti}$ [22]. The excellent intrinsic magnetic properties measured on single crystalline samples $\left(K_{l}, M_{s}\right)$ and the high 
value of the hardness parameter $\kappa$ cannot guarantee the direct use of the material for permanent magnet production. Indeed, each class of hard magnetic material requires its own special microand nanostructure, which needs to be controlled by utilizing peculiarities of the phase diagram and solid-state phase transformations. More importantly, in the context of this work, defects resulting from phase formation under specific processing regimes can serve as centers where reverse magnetic domains nucleate and propagate even in weak magnetic fields, thereby drastically reducing the coercivity of the sample. Due to the above mentioned promising intrinsic properties, the $\mathrm{SmFe}_{11} \mathrm{Ti}$ material is selected as a prototypical representative for $\mathrm{ThMn}_{12}$-type materials.

Figure 1 compares coercivity values from literature of benchmark $\mathrm{Nd}_{2} \mathrm{Fe}_{14} \mathrm{~B}$-based materials [2346] and $\mathrm{Sm}(\mathrm{Fe}, \mathrm{X})_{12}$-based materials [20, 47-61], as a function of grain size. For the $\mathrm{Nd}_{2} \mathrm{Fe}_{14} \mathrm{~B}$ system coercivity values up to $2.95 \mathrm{~T}$ have been reported for thin films, while coercivity around 1.95 T have been achieved for sintered bulk samples. Even though the Sm-based $\mathrm{ThMn}_{12}$-systems show similar anisotropy field, the reported coercivity values do not surpass $1.1 \mathrm{~T}$ in melt-spun ribbons. The highest coercivity reported for the $\mathrm{ThMn}_{12}$-type bulk system is $1.07 \mathrm{~T}$ for $\mathrm{Sm}_{8} \mathrm{Fe}_{75.5} \mathrm{Ga}_{0.5} \mathrm{Ti}_{8} \mathrm{~V}_{8}$. Recently, coercivities of $1.2 \mathrm{~T}$ and $1.26 \mathrm{~T}$ has been reported for $\mathrm{Sm}\left(\mathrm{Fe}_{0.8} \mathrm{Co}_{0.2}\right)_{12} \mathrm{~B}_{0.5}$ thin films and $\mathrm{Sm}_{0.815} \mathrm{Zr}_{0.185}\left(\mathrm{Fe}_{0.81} \mathrm{Co}_{0.19}\right)_{11.19} \mathrm{Ti}_{0.81}$ mechanochemically synthesized oriented particles, respectively, as indicated by the dashed line in Figure 1. For Sm-FeTi ternary compositions the reported coercivity values do not surpass $0.51 \mathrm{~T}$, as indicated by a dotted line in Figure 1. 


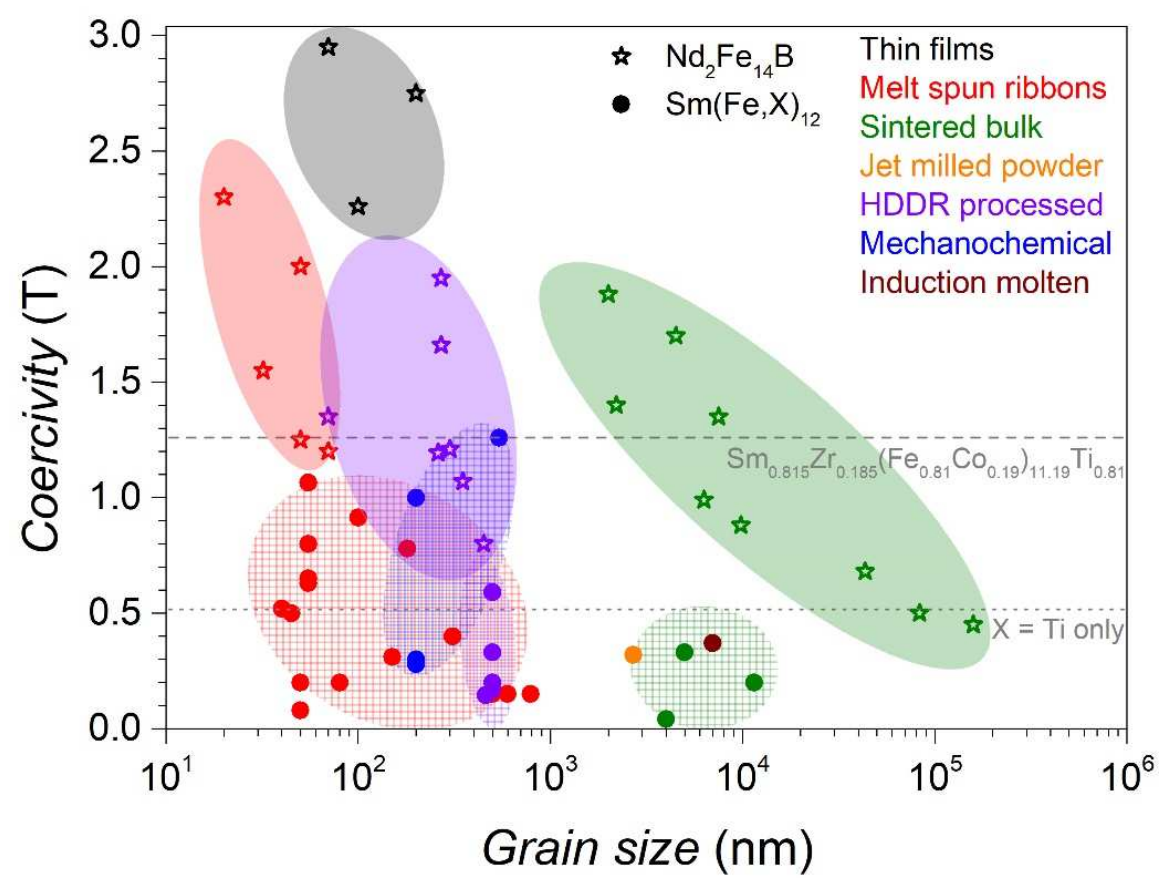

Figure 1. Comparison of reported coercivity values as a function of grain size. Open symbols and full symbols correspond to $\mathrm{Nd}_{2} \mathrm{Fe}_{14} \mathrm{~B}$ and $\mathrm{Sm}(\mathrm{Fe}, \mathrm{X})_{12}$ systems, respectively. Different colors correspond to different sample production methods and shaded areas are guides to the eye. The highest reported coercivity of a $\mathrm{ThMn}_{12}$-type structure is shown by the dashed line [62]. The highest reported coercivity for a ternary $\mathrm{Sm}(\mathrm{FeTi})_{12}$ sample is shown by the dotted line [55].

A possible explanation for the low coercivity of $\mathrm{SmFe}_{11} \mathrm{Ti}$-based magnets may be the absence of a non-magnetic grain boundary phase which magnetically decouples adjacent grains, as found in classical $\mathrm{Nd}_{2} \mathrm{Fe}_{14} \mathrm{~B}$-type sintered magnets [63]. Another reason might be the presence of macroscopic twin boundaries and microscopic slip-bands, which were previously reported in $\mathrm{ThMn}_{12}$-type structures $[50,64,65]$. Although the twins have been observed in different $\mathrm{ThMn}_{12-}$ type material systems before, up to now, their influence on the physical properties were not investigated in detail. It is important to state that there are no reports on twins in high performance magnets based on $\mathrm{Nd}_{2} \mathrm{Fe}_{14} \mathrm{~B}$-, $\mathrm{SmCo}_{5}-\mathrm{Sm}_{2} \mathrm{Co}_{17}$ and $\mathrm{Sm}_{2} \mathrm{Fe}_{17} \mathrm{~N}_{\mathrm{x}}$-type rare earth transition metal phases. In contrast and equally important, a mixture of stacking faults, anti-phase boundaries and 
abundant twins have been shown to occur in rare earth free $\mathrm{L} 1_{0}$-type hard magnetic phases. For the Fe-Pd, Fe-Pt and Co-Pt systems twins conjugate along $\{110\}$-planes, while for MnAl systems twins conjugate along $\{111\}$-planes. These twins can form during a diffusional transformation or recrystallization [66-74]. In 2001, Attané et al., reported that micro-twins observed in FePt films act as pinning centers that increase coercivity [75]. Microscopic twins and stacking faults observed in Co-based high-density magnetic recording media materials such as $\mathrm{CoCr}$ and $\mathrm{CoCrPt}$ were also credited with increasing coercivity [76, 77]. On the other hand, twins in Mn-Al have been reported to be deleterious for coercivity, by decreasing locally the energy necessary to nucleate reversed magnetic domains [78]. The bivalent role that twins appear to play in different hard magnetic material systems highlights the importance of a deeper understanding of the link between microstructure and magnetic properties in such technologically important materials.

To date, no detailed investigation has been reported on the nature of twins in $\mathrm{SmFe}_{11} \mathrm{Ti}$-based compounds and their effect on the hard-magnetic properties. In this study, we address this issue by comprehensively investigating twins at different length-scales in (1) twinned bulk crystals, (2) poly-crystalline bulk samples and (3) poly-crystalline thin films. At various stages we also refer to the benchmark $\mathrm{Nd}_{2} \mathrm{Fe}_{14} \mathrm{~B}$ to elucidate commonalities and disparities. We reveal changes in atomic ordering across twin-like structures and a change in composition at the twin boundaries with respect to the adjacent lattice, using advanced electron microscopy and atom probe tomography. Micromagnetic modelling support our experimental results and elucidate how twins influence local and global magnetization reversal and ultimately macroscopic hysteresis properties in the $\mathrm{SmFe}_{11} \mathrm{Ti}$ system. We also consider how twin formation is associated with the accumulation of internal 
stresses during solidification and grain growth during thermal treatments, as a consequence the energy of the twin formation is becoming more favoured in comparison to the formation of specific grain boundaries. Molecular dynamics shows that there is a fine balance between twin formation and certain grain boundary phases. In this work, we study in detail on all length scales how twins act as a weak link in the magnetic hardening of $\mathrm{ThMn}_{12}$-type permanent magnets.

\section{Experimental and Simulation Details}

Poly-crystalline and single-crystalline sample preparation and characterization: Polycrystalline $\mathrm{Sm}_{1.25} \mathrm{Fe}_{11} \mathrm{Ti}$ ingots were prepared by melting high-purity (>99.99\%) starting elements in an induction furnace under a purified argon atmosphere. Using an arc-melting setup, the ingot was suction-cast into a rectangular slab of $0.5 \mathrm{~mm}$ thickness, to ensure fast solidification/cooling (approx. $10^{3} \mathrm{~K} \cdot \mathrm{s}^{-1}$ ). The suction-cast slabs were wrapped in Mo foil, sealed in quartz ampules under Ar atmosphere and annealed at $1175^{\circ} \mathrm{C}$ for 30 minutes to stabilize the $\mathrm{Sm}(\mathrm{Fe}, \mathrm{Ti})_{12}$ phase and then quenched in room temperature water. It is worth mentioning that an off-stoichiometric (higher Sm concentration) composition was used to compensate for evaporation losses during the melting and annealing procedures.

Structural characterization and phase determination of the annealed samples were done using room temperature X-ray powder diffraction (XRD). The measurements were carried out on a Stoe Stadi $\mathrm{P}$ diffractometer with $\mathrm{Mo} \mathrm{K} \alpha_{1}$ radiation, in transmission mode and an angular $2 \theta$ range from $5^{\circ}$ to $50^{\circ}$. Phase matching and structural refinements were performed using FullProf software [79]. Microstructural analysis was carried out using a Tescan VEGA3 scanning electron microscope (SEM) with secondary electron (SE) and backscattered electron (BSE) detectors. The chemical 
composition of the observed phases was determined by energy-dispersive X-ray spectroscopy (EDS) measurements.

Magneto-optical Kerr effect (MOKE) measurements were performed on a Zeiss Axio Imager.D2m microscope with polarized light function equipped with an electromagnet (evico magnetics $\mathrm{GmbH}$ ). The MOKE measurements were done using polar contrast mode to ensure highest contrast between the magnetic domains pointing in opposite directions. To enhance the magnetic contrast of the images, the non-magnetic background image was subtracted from the measurement images by using the KerrLab software.

$\mathrm{SmFe}_{11} \mathrm{Ti}$ single crystals were produced by re-melting $\mathrm{Sm}_{1.25} \mathrm{Fe}_{11} \mathrm{Ti}$ polycrystalline samples and then slowly cooling them at a rate of $1{ }^{\circ} \mathrm{C} / \mathrm{h}$. Re-melting was carried out in a $\mathrm{ZrO}_{2}$ crucible in a sealed quartz tube under a protective Ar atmosphere. The obtained particles, of typical size 500$1000 \mu \mathrm{m}$, were mechanically separated from each other and they are referred as twinned crystals. Selected crystals were oriented using back-scattering Laue x-ray diffraction and mounted for magnetic characterization along three different directions: [100], [110] and [001]. Magnetic measurements were performed at room temperature using a PPMS-VSM (Quantum Design PPMS14) under external applied magnetic fields of up to $14 \mathrm{~T}$. For investigation of magnetic domain structures by the MOKE technique, two twinned single crystals were used. The observation surface of one crystal was polished perpendicular to the [100] direction (in-plane magnetization) and that of the other perpendicular to the [001] direction (out-of-plane magnetization). 
Thin film sample preparation and characterization: Sm-based 1:12-type films of thickness $1.5 \mu \mathrm{m}$ were deposited by triode sputtering onto thermally oxidized Si wafers at $700{ }^{\circ} \mathrm{C} .50 \mathrm{~nm}$ Ta buffer layers were used to prevent chemical reaction between the wafer and the magnetic layer and $10 \mathrm{~nm}$ Ta capping layers were added to prevent oxidation. We present results from two samples with composition $\mathrm{Sm}_{0.7} \mathrm{Fe}_{11.3} \mathrm{Ti}_{0.9}$ and $\mathrm{Sm}_{0.7} \mathrm{Zr}_{0.2} \mathrm{Fe}_{11.4} \mathrm{Ti}_{0.7}$, as estimated by EDS, referred to as the $\mathrm{Sm}(\mathrm{Fe}, \mathrm{Ti})_{12}$ film and the $(\mathrm{Sm}, \mathrm{Zr})(\mathrm{Fe}, \mathrm{Ti})_{12}$ film, respectively. Atomic structure and diffraction analysis of the films were carried out using transmission electron diffraction (TEM) microscopy. TEM samples were prepared in cross-sectional configuration by mechanical polishing (down to 25 $\mu \mathrm{m})$ followed by ion milling with a Gatan PIPS II (Precision Ion Polishing System). Ion milling of the TEM samples was performed at $3 \mathrm{kV}$ for several hours until an electron transparent hole appears, followed by 5 minutes of cleaning at $0.5 \mathrm{kV}$.

High resolution microscopy on polycrystalline samples: To locate grains with twin boundaries, electron backscatter diffraction (EBSD) analysis was performed on the polycrystalline samples using a Jeol JSM-6500F SEM operated at $15 \mathrm{kV}$. EBSD acquisition was performed using the TSL OIM EBSD system equipped with a Digiview IV EBSD detector with a step size of $0.1 \mu \mathrm{m}$. Correlative electron microscopy and atom probe tomography (APT) investigations were carried out using a JEOL 2200FS aberration-corrected electron microscope (Thermo-Fischer TITAN) in scanning-transmission (STEM) mode and a local-electrode-atom-probe (LEAP 5000 XR, Cameca) instrument equipped with reflection lens, respectively. For APT, needle-shaped specimens were prepared from the twin boundary regions using a dual beam SEM/focused-ion-beam (FIB) instrument (FEI Helios Nanolab 600i) with an in-situ-lift-out procedure detailed in references [66, 
80, 81]. The prepared lamella, containing the twin boundary region, was positioned and Pt-welded using the in-situ gas-injection system on the electro-polished posts of a halved TEM Mo-grid. The Mo-grid with the attached specimen was held in a special correlative holder designed in-house, as described in reference [82]. The welded regions on the Mo-posts were sharpened by Ga ions accelerated at $30 \mathrm{kV}$ with currents ranging from $80 \mathrm{pA}$ to $0.78 \mathrm{nA}$. The sharpened specimens were checked by TEM to get the exact location of the twin boundary and further Ga-ion milling was performed such that the boundary is within $150 \sim 200 \mathrm{~nm}$ from the apex of the specimen. Before APT analysis, the specimens were cleaned by $5 \mathrm{kV}$ with $8 \mathrm{pA}$ current to remove regions of the specimen severely damaged by the implantation of high-energy Ga-ions.

Near-atomic-scale compositional analysis was performed using a LEAP 5000 XR instrument operated in laser pulsing mode with a pulse repetition of $200 \mathrm{kHz}$ and a pulse energy of $40 \mathrm{pJ}$. The specimen was kept at a base temperature of $60 \mathrm{~K}$ with a target detection rate of 5 ions detected per 1000 pulses. The APT reconstruction and analysis were performed using IVAS 3.8.2 software.

Micromagnetic simulations: Magnetization reversal in a single twinned grain was computed by micromagnetic simulations. The shape of the grain was generated with the Neper software [83]. The twin boundary was defined with the computer aided design software Salome [84]. The geometric model is meshed with tetrahedral finite elements using MeshGems [85]. In order to treat the magnetostatic open boundary problem [86], the finite element mesh for the magnetostatic scalar potential is extended outside the magnetic grains. The mesh size at the grain surfaces and twin boundaries was $1.5 \mathrm{~nm}$. We computed the demagnetization curve by minimization of the Gibbs 
free energy for a decreasing external field. To solve for the next local minimum, we used a preconditioned conjugate gradient method [87]. Plots of the demagnetization curves were created using matplotlib [88].

Molecular dynamics simulations: The molecular dynamics calculations were carried out by using modified Morse potentials on supercell structures with the crystallographic interface orientation and composition taken from experiments. The different surface energies of the 1:12 phase were calculated. The twin formation was incorporated as an additional interface energy contribution. After the total energy with and without twin formation has been derived, we saw that once the grain reaches a certain size, twin formation is deemed preferential. This result underpins the findings in the experiments.

\section{Results and Discussion}

\subsection{Single crystals and intrinsic magnetic properties}

Magnetic anisotropy is the key requisite for achieving a large coercivity, and in the ideal case of uniform rotation of the magnetic moments in single domain particles, the coercivity $H_{c}$ is given by $H_{c}=H_{a}=2 K_{1} / \mu_{0} M_{s}\left(H_{a}\right.$ is anisotropy field, $K_{1}$ is anisotropy constant, $\mu_{0}$ is the permeability of free space, $M_{s}$ is the spontaneous magnetization). In reality, prediction of $H_{c}$ from $K_{1}$ and $M_{s}$, using the Stoner Wohlfarth model [89], leads to a large overestimation. This is known as Brown's paradox $[2,90,91]$, and it is attributed to local magnetic softening caused by crystallographic defects, strain, secondary phases, magnetic and chemical inhomogeneities which reduce $H_{c}$ to about $\alpha H_{a}(\alpha$ is the "Kronmüller factor", which is related to nano-structural imperfections). As-cast materials often exhibit $\alpha=0.01$, and via sophisticated processing methods, e.g. melt spinning, jet milling, or die 
upsetting, $\alpha$ can reach to 0.25 of the theoretical limit in laboratory-made $\mathrm{Nd}-\mathrm{Fe}-\mathrm{B}$ and Sm-Cobased magnets.

We start by reporting in Figure 2 the room temperature magnetization curves of a $\mathrm{SmFe}_{11} \mathrm{Ti}$ twinned crystal, with the magnetic field applied along the [100] and [001] directions. The typical behavior of easy-axis magnetocrystalline anisotropy is observed; the data measured along the 4-fold symmetry axis [001] clearly identifies this as the easy magnetization direction, leading to a $\mu_{0} M_{\mathrm{s}}=$ $1.17 \mathrm{~T}$ (calculated by converting the mass magnetization to volume magnetization considering the x-ray density of the $\left.\mathrm{SmFe}_{11} \mathrm{Ti}\right)$. At room temperature, curves recorded along the [100] and [110] directions are practically identical (the [110] curve is not shown), reflecting a weak magnetic anisotropy within the basal plane of this system at room temperature (see supplementary materials for details of the crystal structure). The anisotropy field, $\mu_{0} H_{a}$, estimated from the slope change in the magnetic hard [100]-axis curve (identified by an arrow in Figure 2), amounts to $10.5 \mathrm{~T}$ at 300 $\mathrm{K}$. The value of $K_{l}$ is estimated to be $627 \mathrm{~J} / \mathrm{kg}$ (approx. $4.8 \mathrm{MJ} / \mathrm{m}^{3}$, considering the theoretical xray density). The hard-axis magnetization curve does not reach the same maximum value as the easy-axis curve above $\mu_{0} H_{a}$, due to anisotropy of the magnetic moment. This observed difference of the easy and hard axes magnetization values above the anisotropy field indicates a possible anisotropy of the magnetization, as has been reported for different rare-earth transition-meal systems [92-94]. Additionally, the low field region of the hard axis measurements shows non-linear behavior which is due to the formation of twins in the "single-crystals". The dashed red line corresponds to the hard axis measurement of a twin-free $\mathrm{SmFe}_{11} \mathrm{Ti}$ single crystal, as reported in [95]. 


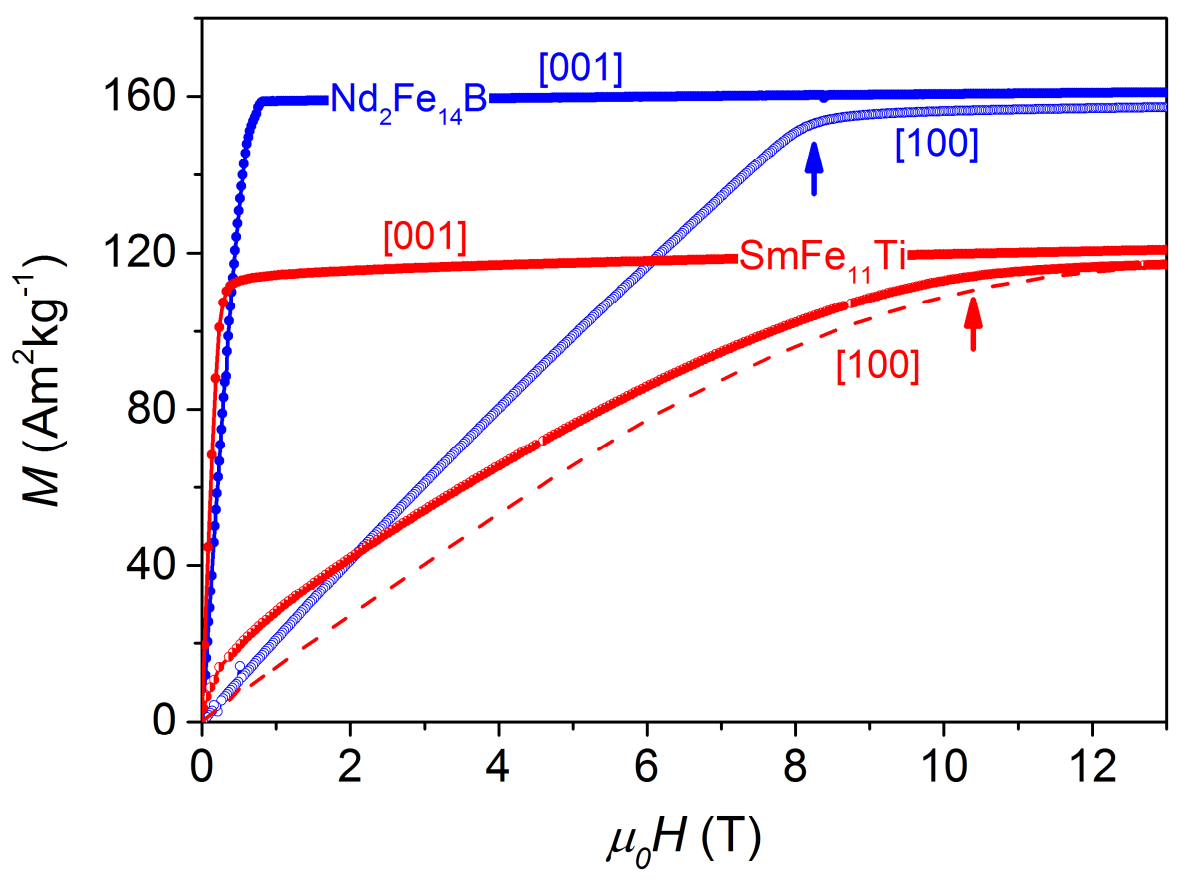

Figure 2. Comparison of room temperature magnetic measurements of $\mathrm{Nd}_{2} \mathrm{Fe}_{14} \mathrm{~B}$ (blue) and $\mathrm{SmFe}_{11} \mathrm{Ti}$ (red) twinned "single-crystals" along easy and hard magnetization directions. The dashed red line indicates the magnetization behavior of a twin-free single crystal along the [100] direction [95].

For comparison, Figure 2 shows the magnetization curves of a $\mathrm{Nd}_{2} \mathrm{Fe}_{14} \mathrm{~B}$ single crystal, measured along [001] and [100], corresponding to the easy and hard magnetization directions, respectively. One can see that the spontaneous magnetization of the $\mathrm{Nd}_{2} \mathrm{Fe}_{14} \mathrm{~B}$ single crystal is significantly higher than that of the $\mathrm{SmFe}_{11} \mathrm{Ti}$ single crystal. On the other hand, the anisotropy field of $\mathrm{SmFe}_{11} \mathrm{Ti}$ is larger than that of $\mathrm{Nd}_{2} \mathrm{Fe}_{14} \mathrm{~B}$.

Next it is instructive to compare the magnetic domain structures imaged by Kerr microscopy of 0.5-1 mm-sized single crystals of $\mathrm{Nd}_{2} \mathrm{Fe}_{14} \mathrm{~B}$ (Figure 3a,b) and $\mathrm{SmFe}_{11} \mathrm{Ti}$ (Figure 3c,d). One can see that for the $\mathrm{Nd}_{2} \mathrm{Fe}_{14} \mathrm{~B}$ single crystal, the branched domain pattern on the basal plane (Figure $3 \mathrm{a}$, the c axis and magnetization are perpendicular to the crystal surface) and stripe-like domains on the 
prismatic plane (Figure 3b, the $\mathrm{c}$ axis and magnetization lie in the plane of the image) are rather periodic and without significant distortions. In contrast, the domain structures of the $\mathrm{SmFe}_{11} \mathrm{Ti}$ twinned crystal (Figure 3c) are locally distorted (highlighted by the arrow), and this is more pronounced when the magnetization lies in the plane of the image (Figure 3d). Such step-like features observed on stripe magnetic domains are a signature of the presence of a crystallographic twinning structure, and this phenomenon was well-studied in other materials, such as magnetic shape memory materials [96, 97], and materials showing giant magnetostriction [98, 99].

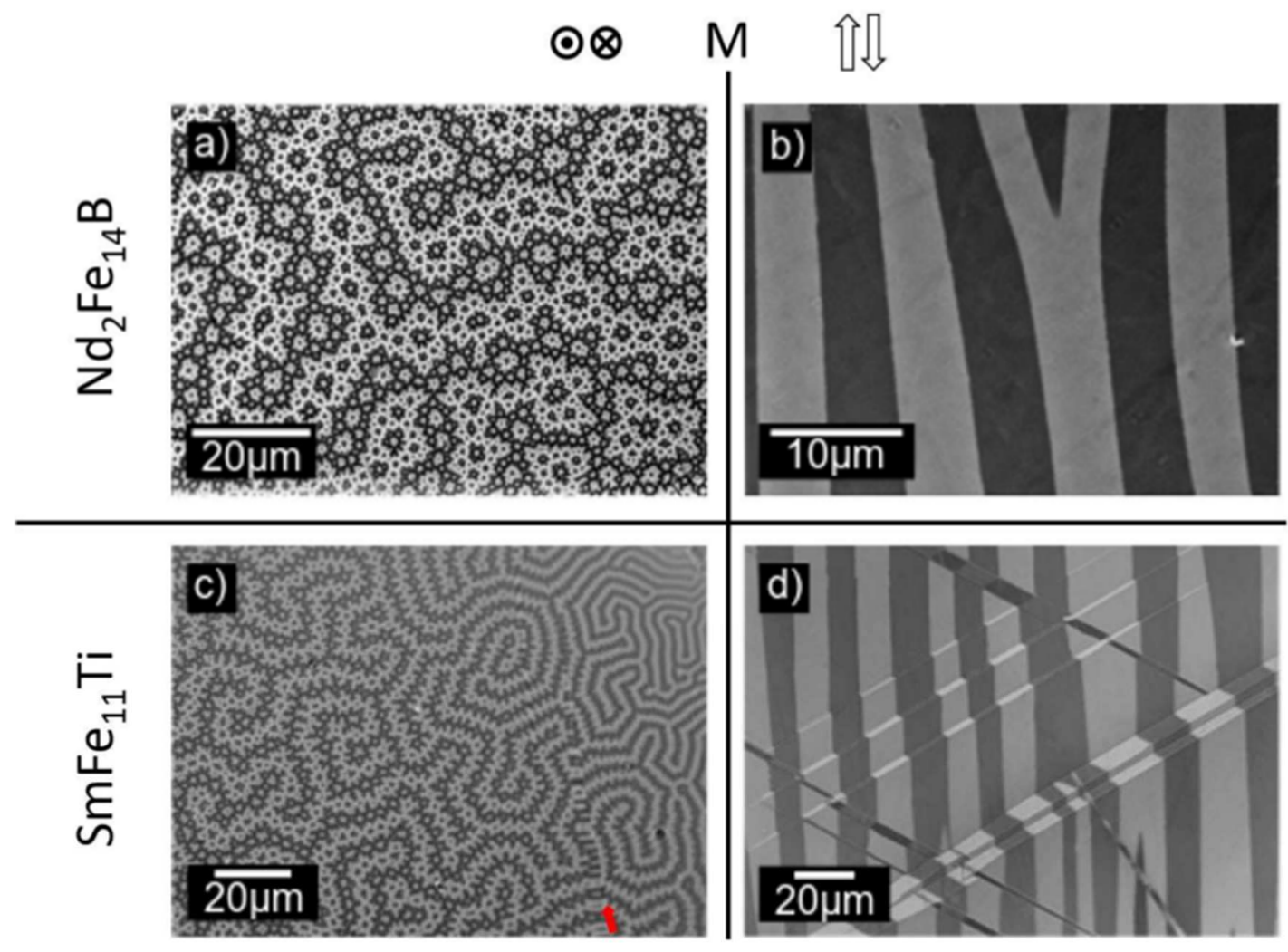

Figure 3. Comparison of room temperature Kerr microscopy images of (a,b) $\mathrm{Nd}_{2} \mathrm{Fe}_{14} \mathrm{~B}$ and (c,d) $\mathrm{SmFe}_{11} \mathrm{Ti}$ twinned single-crystals along easy and hard directions.

In contrast to the $\mathrm{Nd}_{2} \mathrm{Fe}_{14} \mathrm{~B}$ single crystal, the microstructure of the $\mathrm{SmFe}{ }_{11} \mathrm{Ti}$ crystal comprises a significant number of crystallographic twins, which leads to the appearance of micrometer-sized 
blocks of changing orientation. As a result, the magnetization curve measured in the hard direction of the $\mathrm{SmFe}_{11} \mathrm{Ti}$ crystal (Figure 2) is not linear but exhibits a kink at low fields - i.e. a "softmagnetic like" curvature, which is not observable in the $\mathrm{Nd}_{2} \mathrm{Fe}_{14} \mathrm{~B}$ single crystal.

\subsection{Polycrystalline samples}

Figure 4 shows the magnetic domain structures of Nd-Fe-B and Sm-Fe-Ti polycrystalline bulk samples. The domain patterns were observed on arbitrarily oriented polished surfaces of isotropic samples. In $\mathrm{Nd}_{2} \mathrm{Fe}_{14} \mathrm{~B}$ grains, Figure $4 \mathrm{a}$, the domain structure is rather uniform and the domain pattern changes only across grain boundaries, i.e. due to the different crystallographic orientation of adjacent grains. In contrast, the domain structure of the $\mathrm{SmFe}{ }_{11} \mathrm{Ti}$ grains, Figure $4 \mathrm{~b}$, is often divided in two (or more) well distinguishable patterns by a twin boundary, some of which are marked by red arrows. 

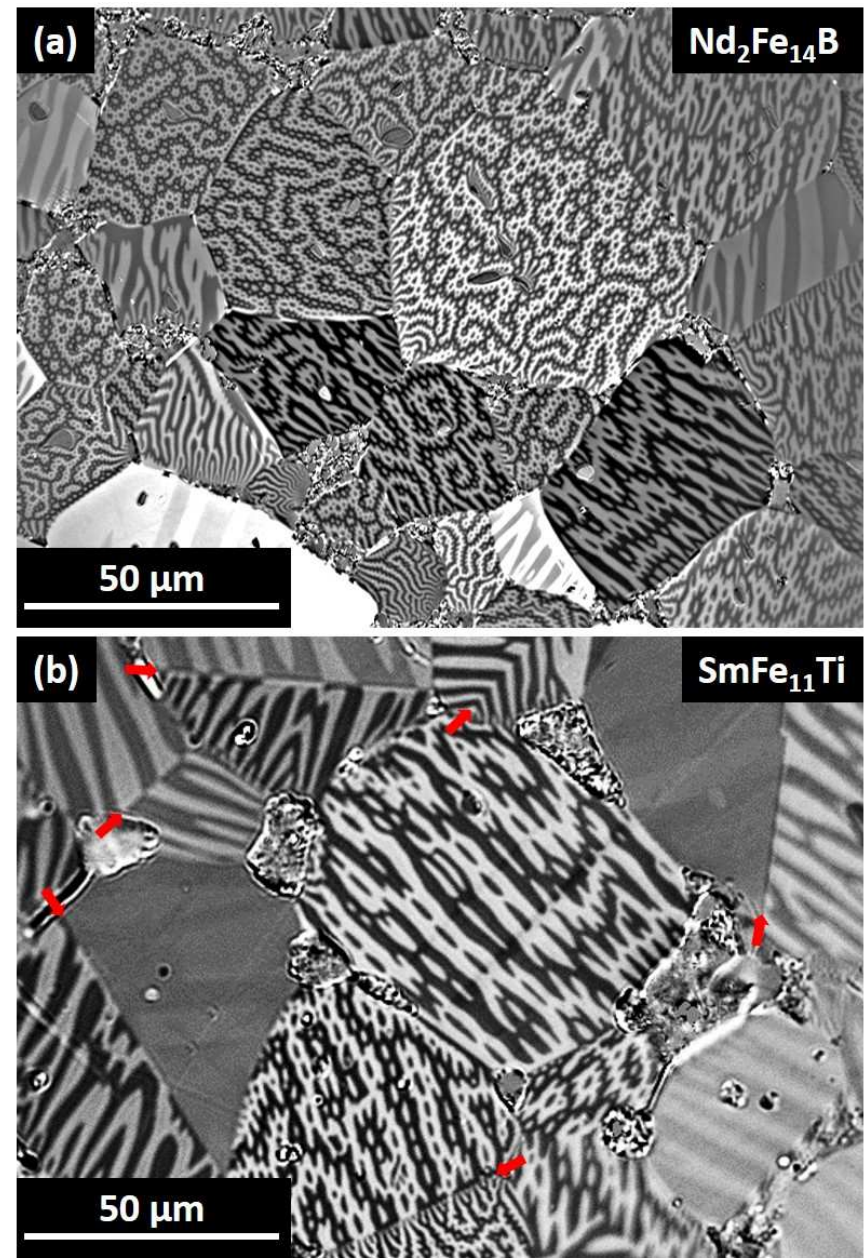

Figure 4. Comparison of room temperature Kerr microscopy images of polycrystalline (a) $\mathrm{Nd}_{2} \mathrm{Fe}_{14} \mathrm{~B}$ and (b) $\mathrm{SmFe}_{11} \mathrm{Ti}$ bulk samples. Red arrows indicate some of the twins observed in the $\mathrm{SmFe}_{11} \mathrm{Ti}$ sample.

Figure 5a shows an electron back scattered diffraction (EBSD) map of the $\mathrm{SmFe}{ }_{11}$ Ti polycrystalline bulk sample evidencing grains with different orientations. The EBSD map was indexed as $\mathrm{Sm}(\mathrm{Fe}, \mathrm{Ti})_{12}(1: 12$ phase) matrix phase having a tetragonal crystal structure (space group $\mathrm{I} / \mathrm{mmm}$ ) with lattice parameters $a=b=0.8589 \mathrm{~nm}$ and $c=0.4807 \mathrm{~nm}$. Some grains contain unique boundaries corresponding to twins, such as the region within the black-dashed rectangle in Figure 5a. The twin orientation relation between the twin variants is approximately $57^{\circ}$, as shown Figure 
5b. We also show a schematic view of the orientation with respect to the shared twin boundary, and found that the twinning boundary plane corresponds to $\{011\}$-type planes in the unit cell of the $\mathrm{Sm}(\mathrm{Fe}, \mathrm{Ti})_{12}$ phase. Figure 5c shows a back scattered electron (BSE) micrograph for a similar twinned region with a twin boundary inside a grain.

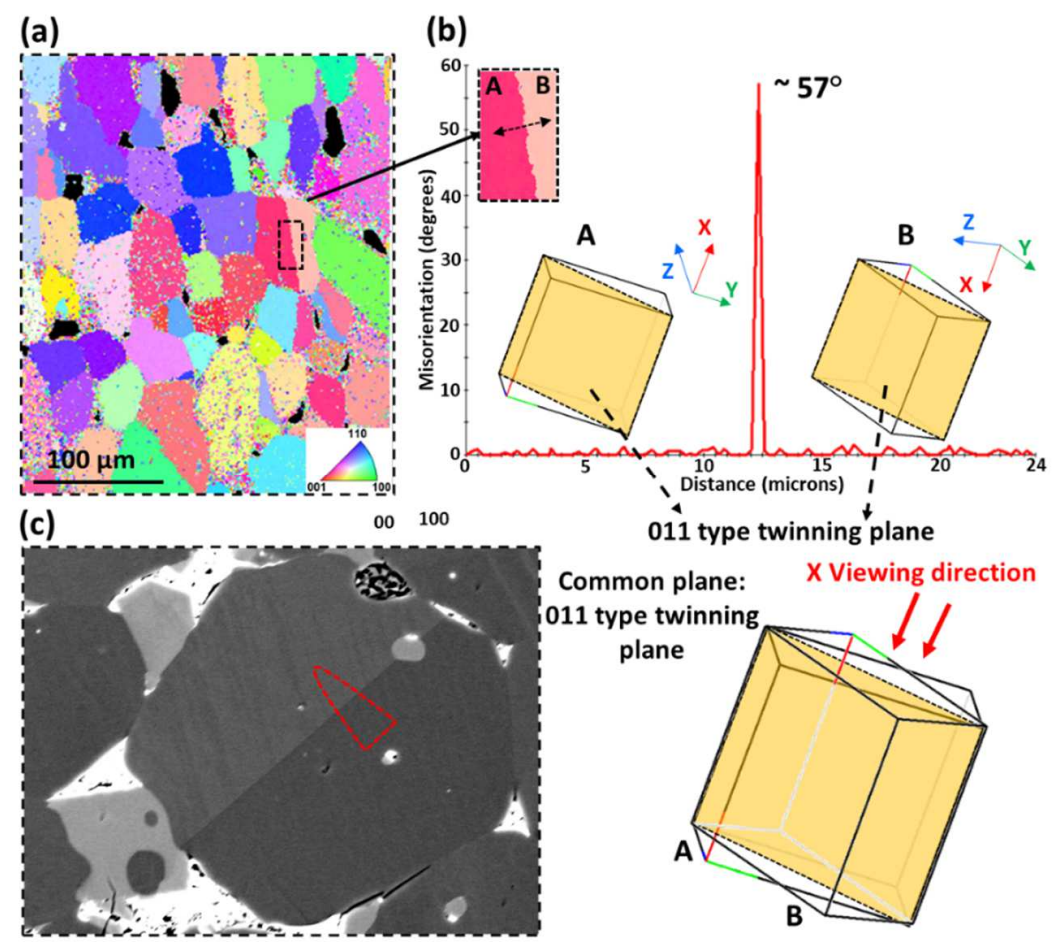

Figure 5. (a) Inverse pole figure image of the investigated polycrystalline $\mathrm{SmFe}_{11} \mathrm{Ti}$ bulk sample derived from EBSD SEM data. (b) Measured angle between two neighboring twin variants and corresponding schematic representation of the unit cells. (c) A BSE SEM image of a twinned grain with the location of the APT specimen identified by a red triangle.

We confirmed the crystallographic relationship of two variants of a twin by using electron diffraction analysis and the results can be found in Supplementary Materials.

We prepared an atom probe tomography (APT) specimen specifically from the location marked by the dashed red outline in Figure 5c. Figure 6a is a low magnification high-annular-angle-dark-field (HAADF) image of the specimen with the twin boundary. HAADF provides Z-contrast, i.e. heavier 
atoms appear brighter. Figure $6 \mathrm{~b}$ is a high-resolution (HR) HAADF image taken along the [100] zone axis from the location marked by a black-dashed square in Figure $6 a$. Figure $6 \mathrm{c}$ is a close-up on the unit cell viewed along the [100] zone axis, which can be compared with the simulated unit cell shown in Figure 6d with $\mathrm{Sm}$ in red and Fe/Ti in green. As expected, atomic columns containing Sm appear bright. We can also clearly see the (011) planes, marked at black dashed lines, which exactly resemble the zig-zag twin boundary, schematically shown with a black dashed line in Figure $6 b$.

(a)

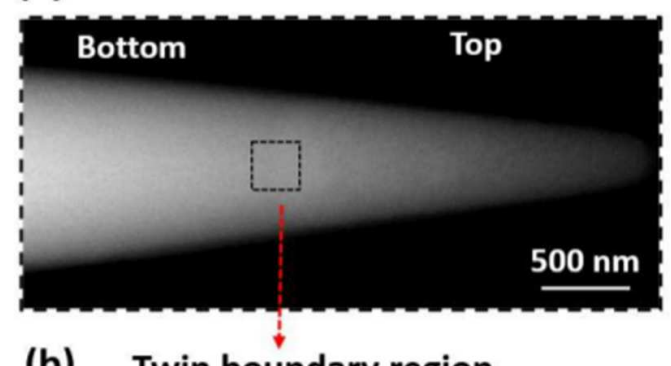

(b) Twin boundary region

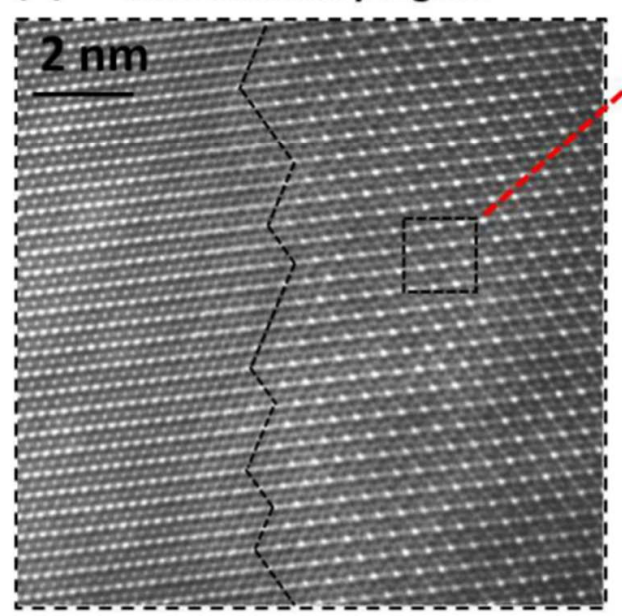

Twin boundary - zig-zag

011 twinning planes (c)

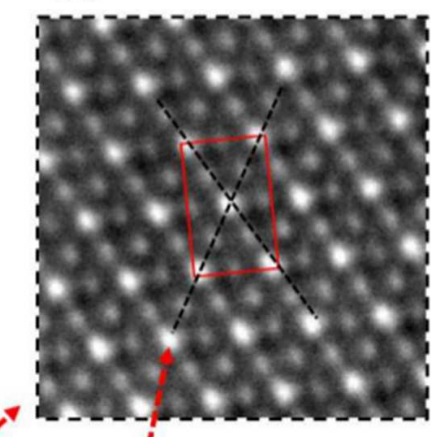

(d)

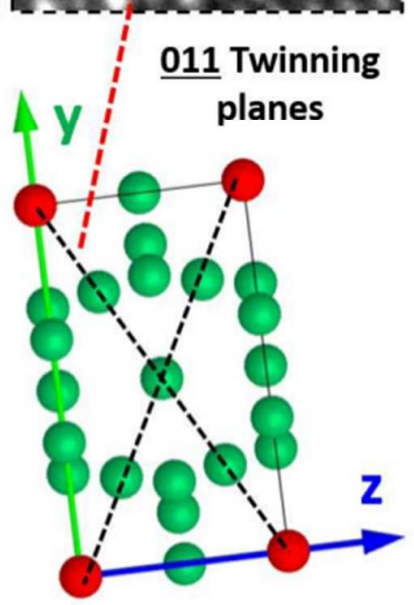

Figure 6. (a) Low magnification HAADF image of $\mathrm{SmFe}_{11} \mathrm{Ti}$ at the twin boundary region. (b) High-resolution HAADF image of the interface region of the twin along the [100] zone axis. (c) High magnification of the twin boundary region and (d) schematic representation of the 011 twinning planes. 
Figure 7 details the results from the APT analysis of the same specimen. Figure 7a is the brightfield electron micrograph of the specimen and Figure $7 \mathrm{~b}$ shows the corresponding APT reconstruction with the distribution of $\mathrm{Fe}, \mathrm{Ti}, \mathrm{Sm}$ atoms and a $\mathrm{Sm} 9$ at.\% iso-composition surface highlighting the location of the twin boundary. Figure 7c shows a 2D Sm compositional map evidencing a local increase in the Sm content at the twin boundary. The measured matrix composition was found to be $\mathrm{Sm}_{7.7} \mathrm{Fe}_{84.3} \mathrm{Ti}_{7.9}$, matching the 1:12 stoichiometry. The composition profile taken across the boundary, Figure 7d, shows a Sm enrichment by approx. 2 at.\% and a depletion of Ti by approx. 2.7 at.\% with respect to the matrix phase. A slight enrichment of Fe, by approx. 0.7 at. $\%$, is also observed. The composition at the twin boundary is close to the stoichiometry of the 3:29-phase i.e. $\mathrm{Sm}_{3}(\mathrm{Fe}, \mathrm{Ti})_{29}$ phase. The electron diffraction measurements (see Figure S2) show no additional spots corresponding to the 3:29-phase, most probably due to the early nucleation stage of the twin boundary phase. 


\section{(a)}

(b)

(c)
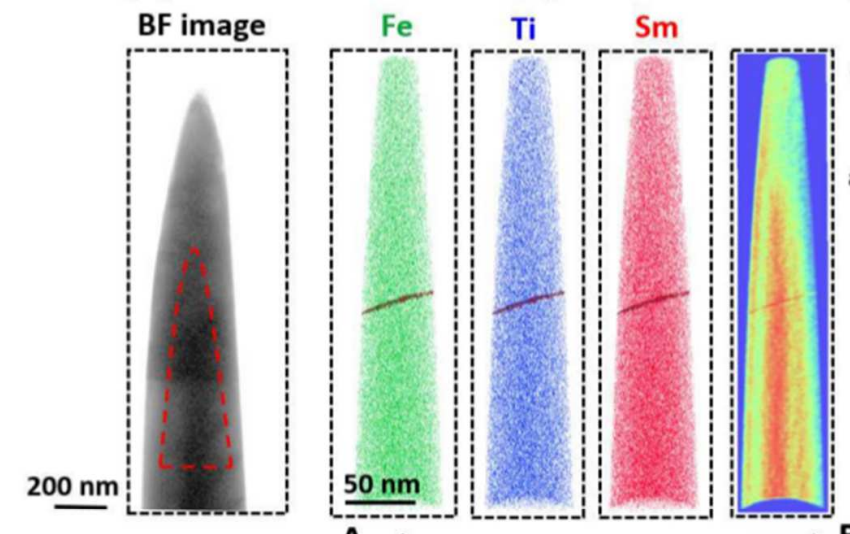

Sm at.\% 2D-

compositional map

$\begin{array}{lllllll}\text { Sm } 10.0 & 9.0 & 8.0 & 7.0 & 6.0 & 5.0\end{array}$

at.\%

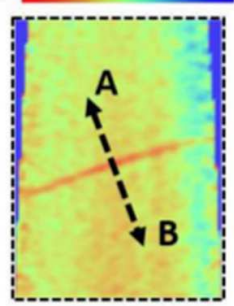

(d)

A

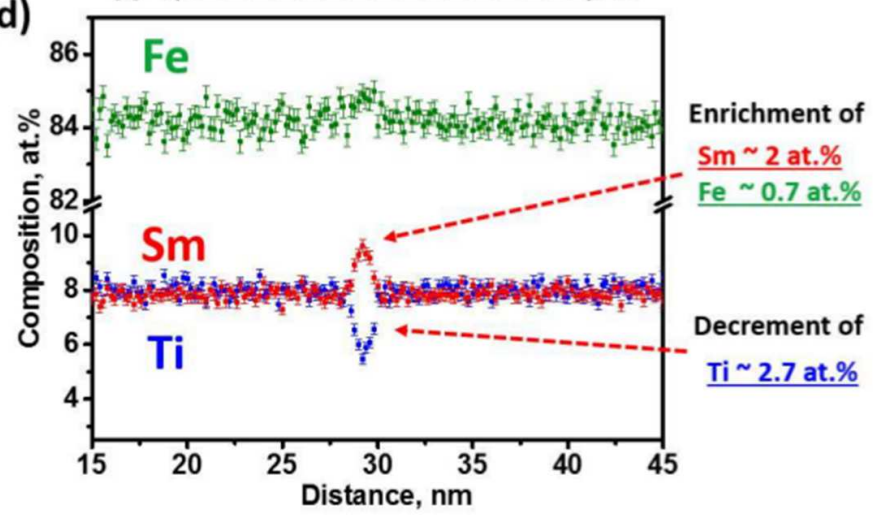

Figure 7. (a) Bright-field image of one of the investigated APT specimens. (b) Atom probe tomography reconstruction of the elemental distribution of Sm, Fe and Ti. (c) 2D compositional map of Sm and (d) chemical composition distribution at the twin boundary region.

To complement the above reported studies of twins in bulk Sm-Fe-Ti samples, we also studied twins in polycrystalline $\mathrm{Sm}-\mathrm{Fe}-\mathrm{Ti}$ and $\mathrm{Sm}-\mathrm{Fe}-\mathrm{Ti}-\mathrm{Zr}$ sputtered films (the latter were studied to probe the eventual influence of $\mathrm{Zr}$ additions in films). Both films contain a first layer of isotropically oriented equiaxed grains of maximum diameter $200 \mathrm{~nm}$, at the interface with the Ta buffer, and elongated grains of width $\sim 200 \mathrm{~nm}$ that traverse the rest of the film thickness. The elongated grains, with lattice parameters corresponding to the $\mathrm{Sm}(\mathrm{Fe}, \mathrm{Ti})_{12}$ structure, are highly textured, with a dominant $\{101\}$ texture. Multiple planar defects oriented parallel to the growth direction, which 
are attributed to twins in the $\mathrm{Sm}(\mathrm{Fe}, \mathrm{Ti})_{12}$ structure, were identified in the elongated grains of both films. A high-resolution micrograph (see Supplementary Materials) shows that along the particular zone axis, the atomic crystal structure on both sides of the twinning boundaries look identical,

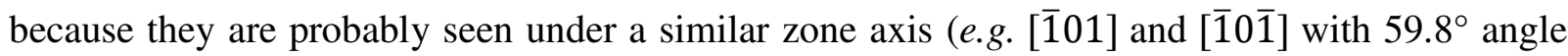
between planes). High-resolution TEM micrographs confirm the formation of twins in polycrystalline film samples, as in their bulk counterparts. For further details and crystallographic phase analysis of the investigated polycrystalline sample please see the Supplementary Materials.

\subsection{Micromagnetic simulations and molecular dynamics calculations}

In an isotropic granular magnet, a grain may be oriented at various directions with respect to the applied external field. For a single domain grain with uniaxial anisotropy and no defect, the demagnetization curves may be very close to the Stoner-Wohlfarth prediction, depending on the direction of the external field. The curve with the minimum switching field will occur when the applied field is oriented at 45 degrees with respect to the anisotropy axis [89]. In this case the switching field will be half of the anisotropy field. Before irreversible switching, the magnetization will rotate reversibly out of the anisotropy axis. In micromagnetic simulations we expect a slight reduction of those switching fields, owing to the self-demagnetizing field of the grain.

We calculated the switching fields of a single twinned $\mathrm{SmFe}_{11} \mathrm{Ti}$ grain as a function of the orientation of the applied external field and compared the results to those of a single uniaxial $\mathrm{Nd}_{2} \mathrm{Fe}_{14} \mathrm{~B}$ grain of the same geometric shape. In the ideal microstructure of a permanent magnet, the grains are separated by a paramagnetic grain boundary phase. Thus, by comparing the single 
grain behavior of $\mathrm{SmFe}_{11} \mathrm{Ti}$ and $\mathrm{Nd}_{2} \mathrm{Fe}_{14} \mathrm{~B}$, we can derive the upper limits of coercivity for both systems.

The shape of the model is shown as an inset of Figure 8a. The volume of the grain was equal to that of a cube with $295 \mathrm{~nm}$ sides. For $\mathrm{Nd}_{2} \mathrm{Fe}_{14} \mathrm{~B}$ calculations we assumed a magnetocrystalline easyaxis parallel to the $z$ direction of the global coordinate system. The intrinsic magnetic properties used were: anisotropy constant $K_{1}=4.9 \mathrm{MJ} / \mathrm{m}^{3}$, magnetization $\mu_{0} M_{\mathrm{s}}=1.61 \mathrm{~T}$, and exchange constant $A=8 \mathrm{pJ} / \mathrm{m}$ (page 401 of [100]). The anisotropy field of this phase is $\mu_{0} H_{a}=7.65 \mathrm{~T}$. To model the effect of a twin in a $\mathrm{SmFe}_{11} \mathrm{Ti}$ grain, we introduced a $6 \mathrm{~nm}$ thick twin boundary $(2.4$ percent of the total volume) parallel to the $x z$-plane which separates the twin variants of the grain into two equally sized halves. The orientation of the two easy-axes of the two variants of the twin are shown as white double-headed arrows and are parallel to the $y z$-plane. The easy-axes enclose an angle of $180-58=122$ degrees, which is consistent with results from EBSD measurements and was checked with the Twiny software [101] which gives $121.5^{\circ}$ for $(011)$ twin planes of $\mathrm{SmFe}_{11} \mathrm{Ti}$. In this model we ignored the experimentally found zig-zag shape of the twin boundary. Test calculations revealed that due to the low amplitude $(1-2 \mathrm{~nm})$ of the pattern, which is smaller than the domain wall width, the zig-zag shape had no effect on our micromagnetic simulations. We used the following intrinsic magnetic properties for SmFe ${ }_{11} \mathrm{Ti}: K_{1}=4.8 \mathrm{MJ} / \mathrm{m}^{3}$ and $\mu_{0} M_{\mathrm{s}}=1.17 \mathrm{~T}$ which are both equal to the measured values for single crystals shown above. This yields an anisotropy field of $\mu_{0} H_{\mathrm{a}}=10.31 \mathrm{~T}$. For the exchange constant we assumed $A=10 \mathrm{pJ} / \mathrm{m}$. For the twin boundary phase, as in agreement with the APT results, we assume a monoclinic ordered $\mathrm{Sm}_{3}(\mathrm{Fe}, \mathrm{Ti})_{29}$ phase. For a monoclinic system the magneto-crystalline anisotropy energy density $K_{1} \sin ^{2} \theta+K_{2} \sin ^{2} \theta \cos 2 \phi$ 
depends not only on the polar angle $\theta$, but also on the azimuthal angle $\phi$. For $\mathrm{Sm}_{3}(\mathrm{Fe}, \mathrm{Ti})_{29}$ the anisotropy constants are $K_{1}=1.8 \mathrm{MJ} / \mathrm{m}^{3}, K_{2}=0.4 \mathrm{MJ} / \mathrm{m}^{3}$ and the magnetization is $\mu_{0} M_{\mathrm{s}}=1.13 \mathrm{~T}$ [102]. For our simulations we ignored the contribution of $K_{2}$ and assumed that the $\mathrm{Sm}_{3}(\mathrm{Fe}, \mathrm{Ti})_{29}$ easy-axis is aligned with one of the easy-axes of two variants of the main phase [102-105].
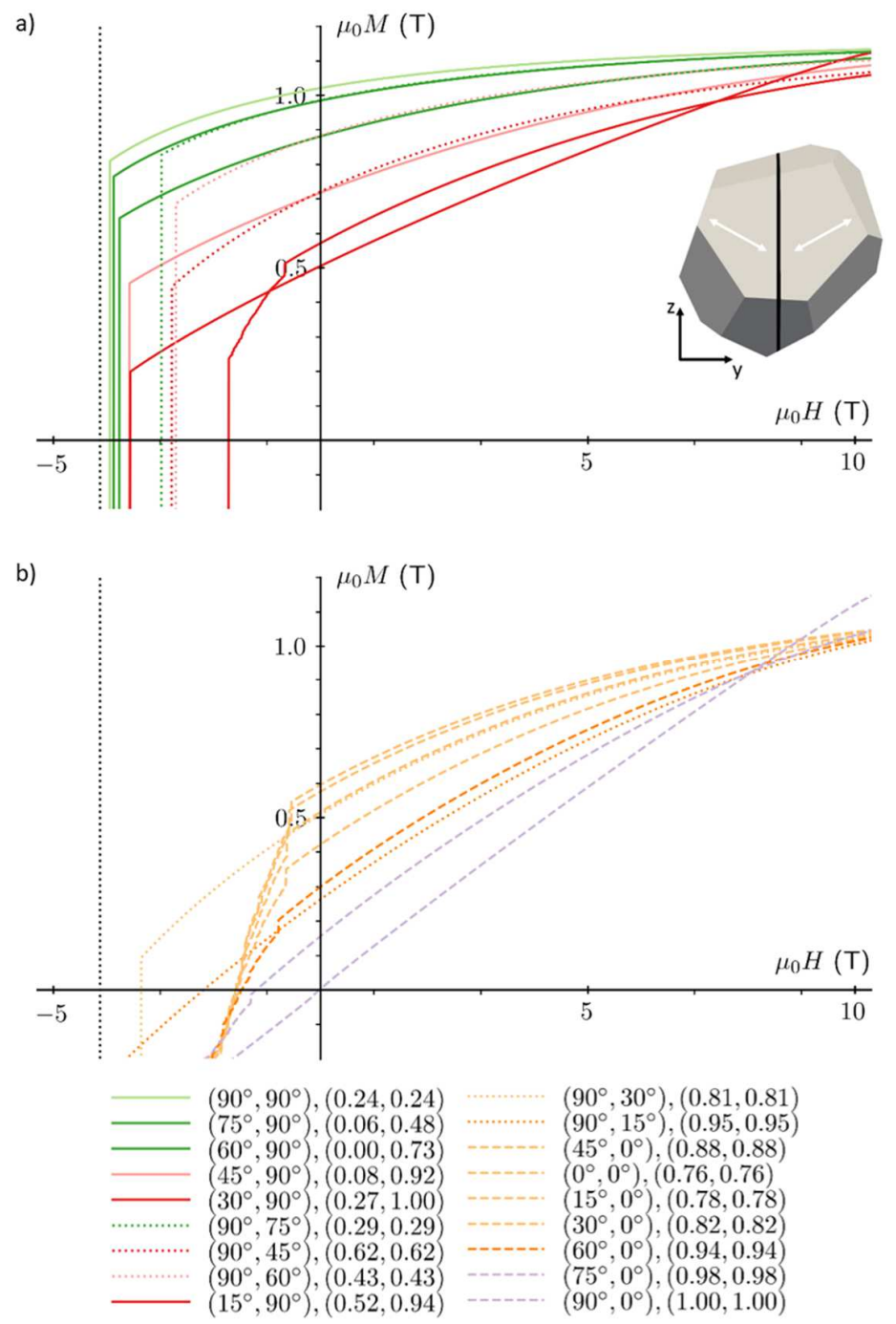

Figure 8. Demagnetization curves as a function of the direction of the external field computed for a single twinned $\mathrm{SmFe}_{11} \mathrm{Ti}$ grain where a $6 \mathrm{~nm}$ thick $\mathrm{Sm}_{3}(\mathrm{Fe}, \mathrm{Ti})_{29}$ twin boundary separates the two 
variants of the main phase. The inset in a) shows the model setup. The twin boundary is parallel to the xz-plane. The two easy-axes of the two variants are shown as white double-headed arrows and are parallel to the yz-plane. The angle between the two easy-axes is $122^{\circ}$. The direction of the external field is given in the first bracket of the legend entries by spherical coordinates $(\theta, \varphi)$ where $\theta$ is the polar angle $(\mathrm{z}->\mathrm{x})$ and $\varphi$ is the azimuthal angle $(\mathrm{x}->\mathrm{y})$. The second bracket gives $\sin ^{2} \alpha_{i}$ where $\alpha_{\mathrm{i}}$ is the angle enclosed by the external field direction and one of the two easy-axes of the twin variants. $\sin ^{2} \alpha_{i}$ is proportional to the magnetocrystalline anisotropy energy density. Color changes from green to purple in $10^{\circ}$ steps of the average $\alpha$. Solid, dashed and dotted lines group similar rotation directions of the external field from $\mathrm{z}$ to $\mathrm{y}, \mathrm{z}$ to $\mathrm{x}$, and $\mathrm{x}$ to $\mathrm{y}$, respectively. Entries in the legend are sorted by coercive field. a) shows the easy-axis-like demagnetization curves where average $\alpha\left\langle 61^{\circ}\right.$, b) shows the hard-axis-like curves with average $\left.\alpha\right\rangle=61^{\circ}$. The dotted black line on the left-hand side marks 40 percent of the anisotropy field of SmFe ${ }_{11} \mathrm{Ti}$.

The orientation of the external field is given in spherical coordinates $(\theta, \varphi)$ where $\theta$ is the polar angle $(z \rightarrow x)$ and $\varphi$ is the azimuthal angle $(x \rightarrow y)$. The angle between the applied field and the magnetocrystalline easy-axis is given by $\alpha_{i}$ where $i$ refers to one of the two variants of the $\mathrm{SmFe}_{11} \mathrm{Ti}$ phase. $\alpha$ is the average angle given by $\alpha=\left(\alpha_{1}+\alpha_{2}\right) / 2$. The anisotropy energy density is given by $E_{a}=K_{1} \sin ^{2} \alpha_{i}$. The switching field is defined as the first kink in the demagnetization curve when the behavior changes from reversible rotation to irreversible nucleation of reversed domains. The micromagnetic simulations for a $\mathrm{Nd}_{2} \mathrm{Fe}_{14} \mathrm{~B}$ grain without a defect (graphs not shown) give switching field $\left(\mu_{0} H_{\mathrm{sw}}\right)$ values that vary between $-5.42 \mathrm{~T}$ for $\theta=1^{\circ}$ and $-3.23 \mathrm{~T}$ for $\theta=45^{\circ}$. This corresponds to 71 percent or 42 percent of the anisotropy field of $\mathrm{Nd}_{2} \mathrm{Fe}_{14} \mathrm{~B}$, respectively. The switching field of all other computed orientations of the external field were between those values, consistent with Stoner-Wohlfarth results mentioned above, and also considering selfdemagnetizing effects.

In contrast, despite the higher anisotropy field of the $\mathrm{SmFe}_{11} \mathrm{Ti}$ phase, much lower switching fields were found for $\mathrm{SmFe}_{11} \mathrm{Ti}$, due to the twin defect. Figure 8 shows demagnetization curves for 
various orientations of the external field computed for a twinned $\mathrm{SmFe}_{11} \mathrm{Ti}$ grain split by a single $6 \mathrm{~nm}$ thick $\mathrm{Sm}_{3}(\mathrm{Fe}, \mathrm{Ti})_{29}$ twin boundary. Irreversible switching always starts at fields below 40 percent of the anisotropy field of $\mathrm{SmFe}_{11} \mathrm{Ti}$. Switching fields of between $-3.94 \mathrm{~T}$ and $-0.55 \mathrm{~T}$ were found for external field directions of $\left(90^{\circ}, 90^{\circ}\right)$ and $\left(0^{\circ}, 0^{\circ}\right)$, respectively. This corresponds to 38 percent and 5 percent of the anisotropy field of $\mathrm{SmFe}_{11} \mathrm{Ti}$, respectively. Please note that the curvature seen in the hard axis loop of Figure 2 of the single crystal measurements could not be reproduced by our model, see $\left(90^{\circ}, 0^{\circ}\right)$ in Figure 8 . Similarly, we did not observe any curvature in the hard axis loop for a reference calculation with zero magneto-crystalline anisotropy $\left(K_{1}=0\right)$ in the twin boundary phase. The contribution of the twin boundary phase to the total magnetization is negligible as its volume fraction is only 2.4 percent of the total volume. A possible reason for the curvature might be canting between the Fe and the Sm sublattices. The switching field strongly depends on the field angle. The magnetocrystalline anisotropy energy density is proportional to $K_{1} \sin ^{2} \alpha$. The lowest switching fields are found if the average $\alpha$ is greater than $61^{\circ}$.

Due to the small thickness of the $\mathrm{Sm}_{3}(\mathrm{Fe}, \mathrm{Ti})_{29}$ phase at the twin boundary, it is not clear if the assumption of a uniaxial magnetocrystalline anisotropy is valid. Thus, we also considered the twin boundary phase to be a soft defect with $K_{l}=0$. The switching fields were then in the range of -3.56 $\mathrm{T}$ to $-1.3 \mathrm{~T}$. In this case, the spread of the switching field values with field angle was reduced from 35 percent to 13 percent of the anisotropy field of $\mathrm{SmFe}_{11} \mathrm{Ti}$.

If we reuse the geometric model of the twin and change the setup of the $\mathrm{Nd}_{2} \mathrm{Fe}_{14} \mathrm{~B}$ single grain simulations to consider a $6 \mathrm{~nm}$ wide $\mathrm{Nd}_{20} \mathrm{Fe}_{80}$ ferromagnetic grain boundary phase $\left(K_{l}=0, \mu_{0} M_{s}=\right.$ 
$0.93 \mathrm{~T}, A=9.99 \mathrm{pJ} / \mathrm{m}$ [106]) but keep the easy-axes of both grains next to the boundary parallel to $z$, the switching field is also reduced to a range of 35 percent to 26 percent of the $\mathrm{Nd}_{2} \mathrm{Fe}_{14} \mathrm{~B}$ anisotropy field. As mentioned before, in $\mathrm{Nd}_{2} \mathrm{Fe}_{14} \mathrm{~B}$ permanent magnets, Nd-rich grain boundary phases with low or no magnetization are believed to magnetically decouple grains and, therefore, increase coercivity in an isotropic granular bulk magnet. Even if a similar grain boundary phase was found for $\mathrm{SmFe}_{11} \mathrm{Ti}$, the defect due to twinning within the grains remains, and will act as a weak spot for nucleation of reversed domains. The computation of the magnetization distribution at the saddle point for thermal switching identified the twin boundary region as the location where the nucleus of reversed magnetization forms.

Summarizing at this point, even if a similar grain boundary phase was found for $\mathrm{SmFe}_{11} \mathrm{Ti}$, the defect due to twinning within the grains remains, and will act as a weak spot for nucleation of reversed domains. The computation of the magnetization distribution at the saddle point for thermal switching identified the twin boundary region as the location where the nucleus of reversed magnetization forms for the geometry shown in Figure 8. It is well known that ferromagnetic exchange coupling between crystallites with different orientations of the easy axes reduces the coercive field [107]. This holds for misoriented, exchange coupled grains as well as for twinned grains with a well-defined orientation relationship between the easy axes of two variants of the twinned grains. From a micromagnetic point of view, in both cases the formation of a partial domain wall causes the nucleation of reversed domains. Table 1 summarizes the micromagnetic simulations giving the hard magnetic phase, the model setup, and the range of the switching field due to the orientation of the external field. 
Table 1. Range of the switching field due to the orientation of the external field for different geometries obtained by micromagnetic simulations. The columns refer to the main hard magnetic phase, the micromagnetic model setup and the coercivity range relative to the anisotropy field of the hard magnetic phases. The volume of the polyhedral grain was equal to that of a cube with an edge length of $295 \mathrm{~nm}$.

\begin{tabular}{|c|c|c|}
\hline Material & Model setup & $\begin{array}{l}\text { Switching field } \\
\text { range (relative to } \\
\left.\text { the } H_{a}\right)\end{array}$ \\
\hline \multirow{2}{*}{$\mathrm{SmFe}_{11} \mathrm{Ti}$} & Twinned grain with $6 \mathrm{~nm} \mathrm{Sm} 3(\mathrm{Fe}, \mathrm{Ti})_{29}$ twin boundary & 0.05 to 0.38 \\
\hline & Twinned grain with $6 \mathrm{~nm}$ twin boundary with $K_{l}=0$ & 0.13 to 0.35 \\
\hline \multirow[b]{2}{*}{$\mathrm{Nd}_{2} \mathrm{Fe}_{14} \mathrm{~B}$} & Single grain without defect & 0.42 to 0.71 \\
\hline & $\begin{array}{l}\text { Two aligned grains separated by a } 6 \mathrm{~nm} \text { ferromagnetic } \\
\mathrm{Nd}_{20} \mathrm{Fe} 80 \text { grain boundary phase (same model geometry } \\
\text { as used for single grain simulation) }\end{array}$ & 0.26 to 0.35 \\
\hline
\end{tabular}

$\mathrm{Ab}$ initio informed molecular dynamics calculations indicate that the twin formation energies are low and in the coherent regime. The competition between the formation energies of a twin boundary and a grain boundary are strongly dependent on the grain size and geometry. The molecular dynamics calculations predict that the twin formation is more energetically favourable for the grains of size above 1 micrometre. Additionally, the molecular dynamics calculations indicate that the interface energies play a significant role in twin formation.

\section{Summary \& Conclusions}

We carried out detailed structural characterization of twins in "single crystal" and polycrystalline bulk samples of composition $\mathrm{SmFe}_{11} \mathrm{Ti}$ as well as ternary $\mathrm{Sm}(\mathrm{Fe}, \mathrm{Ti})_{12}$ and $\mathrm{Zr}$-substituted $(\mathrm{Sm}, \mathrm{Zr})(\mathrm{Fe}, \mathrm{Ti})_{12}$ thin films. Twins were observed at micro- and nano-length scales, and it was found that the twin orientation in all sample types is approximately $57 \pm 2^{\circ}$. Thus twins appear to be 
a generic feature of the $\mathrm{Sm}(\mathrm{Fe}, \mathrm{Ti})_{12}$-system. The twin boundary plane corresponds to a $\{011\}$ plane family in the unit cell of $\mathrm{Sm}(\mathrm{Fe}, \mathrm{Ti})_{12}$. The significantly higher density of twins in the thin films compared to the bulk samples may be due to substrate mediated stress. High resolution electron microscopy studies on polycrystalline bulk samples show an enrichment of Sm and a depletion of $\mathrm{Ti}$ at the twin boundary. The composition of the twin boundary is determined to be $\mathrm{Sm}_{9.6} \mathrm{Fe}_{84.9} \mathrm{Ti}_{5.5}$, matching the composition of the $\mathrm{Sm}_{3}(\mathrm{Fe}, \mathrm{Ti})_{29}$ phase, which has a lower anisotropy field. Modification of the intrinsic magnetic properties of the $\mathrm{Sm}_{3}(\mathrm{Fe}, \mathrm{Ti})_{29}$ phase may lead to an enhancement of the coercivity of the $\mathrm{Sm}(\mathrm{Fe}, \mathrm{Ti})_{12}$-systems.

Micromagnetic simulations were carried out with a microstructure reproducing that of bulk samples, and the results show that the formation of twins reduces the estimated coercivity values to $38 \%$ of the expected switching field. The simulation results account for the observation of low coercivity values in twinned $\mathrm{SmFe}_{11} \mathrm{Ti}$ systems which confirms the detrimental effect of twins. Additionally, the fixed angle between neighboring twin variants would hinder obtaining perfect texture which also would reduce the remanent magnetization significantly.

Formation of twin boundaries in grains larger than 1 micrometre can be attributed to the accumulation of internal stresses during solidification, where twin formation is favoured over the formation of specific grain boundaries. The specific size, morphology and interface energy dependency and the resulting detailed model of the proposed mechanism will be an object of a further study/ publication. 
However, tuning hard magnetic alloys with the intent to render them less prone to twin formation is challenging. Three approaches, having different probabilities of a successful outcome, are conceivable in that context. The first one lies in substitutional compositional modification of the alloy with the aim to increase the twin formation energy which in turn would reduce the tendency for twin formation. However, most of the known reported compositional variants of these materials show twins, irrespective of substitutional variations. Also, twin interface energies are generally so low compared to those of less coherent grain boundaries (i.e. about a factor of 10 smaller) that such effects do not sufficiently alter this relation to reduce their frequency.

The second option lies in exposing the material to heat treatment under stress. This measure bears the risk though that imposing stresses on systems that are already prone to twin formation could lead to more rather than less twins. However, deformation driven twinning is typically reduced at elevated temperatures, where energy dissipation by dislocation activity is often promoted over twin formation, so that this option might be worth exploring.

A third and rather promising pathway is grain size reduction as this change of volume-to-surface energy ratio decreases the need for stress relief via twin formation. For this reason, high coercivities can possibly be achieved in nanocrystalline systems like hot-pressed and die-upset $\mathrm{ThMn}_{12}$-type bulk permanent magnets but are unlikely to be observed in their sintered microcrystalline counterparts. 


\section{Acknowledgments}

This work is partly based on results obtained within the future pioneering program Development of magnetic material technology for high-efficiency motors (MagHEM) commissioned by the New Energy and Industrial Technology Development Organization (NEDO) of Japan. This work was also supported by the Deutsche Forschungsgemeinschaft (DFG, German Research Foundation) Project-ID 405553726 - TRR 270.

\section{References}

1. Gutfleisch, O., M.A. Willard, E. Brück, C.H. Chen, S.G. Sankar, and J.P. Liu, Magnetic Materials and Devices for the $21^{\text {st }}$ Century: Stronger, Lighter, and More Energy Efficient. Advanced Materials, 2011. 23(7): p. 821-842 DOI: 10.1002/adma.201002180.

2. Skokov, K.P. and O. Gutfleisch, Heavy rare earth free, free rare earth and rare earth free magnets - Vision and reality. Scripta Materialia, 2018. 154: p. 289-294 DOI: https://doi.org/10.1016/j.scriptamat.2018.01.032.

3. Hirayama, Y., Y.K. Takahashi, S. Hirosawa, and K. Hono, $\mathrm{NdFe}_{12} \mathrm{~N}_{x}$ hard-magnetic compound with high magnetization and anisotropy field. Scripta Materialia, 2015. 95: p. 70-72 DOI: https://doi.org/10.1016/j.scriptamat.2014.10.016.

4. Hirayama, Y., T. Miyake, and K. Hono, Rare-Earth Lean Hard Magnet Compound $\mathrm{NdFe}_{12} N$. JOM, 2015. 67(6): p. 1344-1349 DOI: 10.1007/s11837-015-1421-9. 
5. Buschow, K.H.J., Structure and properties of some novel ternary Fe-rich rare-earth intermetallics (invited). Journal of Applied Physics, 1988. 63(8): p. 3130-3135 DOI: 10.1063/1.340865.

6. De Mooij, D.B. and K.H.J. Buschow, Some novel ternary ThMn 12 -type compounds. Journal of the Less Common Metals, 1988. 136(2): p. 207-215 DOI: https://doi.org/10.1016/0022$\underline{5088(88) 90424-9 .}$.

7. Coey, J.M.D., Comparison of the intrinsic magnetic properties of $R_{2} \mathrm{Fe}_{14} \mathrm{~B}$ and $\mathrm{R}\left(\mathrm{Fe} \mathrm{I}_{11} \mathrm{Ti}\right)$; $R=$ rare earth. Journal of Magnetism and Magnetic Materials, 1989. 80(1): p. 9-13 DOI: https://doi.org/10.1016/0304-8853(89)90314-4.

8. Hu, B.-P., H.-S. Li, J.P. Gavigan, and J.M.D. Coey, Intrinsic magnetic properties of the iron-rich ThMn $n_{12}$-structure alloys $R\left(F e_{11} T i\right) ; R=Y, N d, S m, G d, T b, D y, H o, E r, T m$ and Lu. Journal of Physics: Condensed Matter, 1989. 1(4): p. 755-770 DOI: 10.1088/0953$8984 / 1 / 4 / 009$.

9. Hirayama, Y., Y.K. Takahashi, S. Hirosawa, and K. Hono, Intrinsic hard magnetic properties of $\operatorname{Sm}\left(\mathrm{Fe}_{1-x} \mathrm{Co}_{x}\right)_{12}$ compound with the $\mathrm{ThMn}_{12}$ structure. Scripta Materialia, 2017. 138: p. 62-65 DOI: https://doi.org/10.1016/j.scriptamat.2017.05.029.

10. Kuno, T., S. Suzuki, K. Urushibata, K. Kobayashi, N. Sakuma, M. Yano, A. Kato, and A. Manabe, $(\mathrm{Sm}, \mathrm{Zr})(\mathrm{Fe}, \mathrm{Co})_{11.0-11.5} \mathrm{Ti}_{1.0-0.5}$ compounds as new permanent magnet materials. AIP Advances, 2016. 6(2): p. 025221 DOI: 10.1063/1.4943051.

11. Hagiwara, M., N. Sanada, and S. Sakurada, Structural and magnetic properties of rapidly quenched $(\mathrm{Sm}, \mathrm{R})(\mathrm{Fe}, \mathrm{Co})_{11.4} \mathrm{Ti}_{0.6}(R=\mathrm{Y}, \mathrm{Zr})$ with ThMn $n_{12}$ structure. AIP Advances, 2019. 9(3): p. 035036 DOI: 10.1063/1.5079949. 
12. Inoue, N. and S. Suzuki, Influence of nitrogenating conditions on magnetic properties of $\mathrm{NdFe}_{8} \mathrm{Co}_{3} \mathrm{TiN}_{x}$. Journal of Alloys and Compounds, 1995. 222(1): p. 82-86 DOI: https://doi.org/10.1016/0925-8388(94)04922-X.

13. Yang, J., O. Mao, and Z. Altounian, Structure and magnetic properties of mechanically alloyed $\mathrm{Nd}(\mathrm{Fe}, \mathrm{V})_{12} \mathrm{~N}_{x}$ compounds. Journal of Applied Physics, 1996. 79(8): p. 5519-5521 DOI: $10.1063 / 1.362296$.

14. Yang, J., W. Mao, B. Cheng, Y. Yang, H. Xu, B. Han, S. Ge, and W. Ku, Magnetic properties and magnetic domain structures of $\mathrm{NdFe}_{10.5 \mathrm{Mo}} \mathrm{1}_{1.5}$ and $\mathrm{NdF} \mathrm{e}_{10.5} \mathrm{Mo}_{1.5} \mathrm{~N}_{x}$. Applied Physics Letters, 1997. 71(22): p. 3290-3292 DOI: 10.1063/1.120315.

15. Yang, J., B. Cui, W. Mao, B. Cheng, J. Yang, B. Hu, Y. Yang, and S. Ge, Effect of interstitial nitrogen on the structural and magnetic properties of $N d F e_{10.5} V_{1.5} N_{x}$. Journal of Applied Physics, 1998. 83(5): p. 2700-2704 DOI: 10.1063/1.366991.

16. Wuest, H., L. Bommer, A.M. Huber, D. Goll, T. Weissgaerber, and B. Kieback, Preparation of nanocrystalline $\mathrm{Ce}_{1-x} \mathrm{Sm}_{x}(\mathrm{Fe}, \mathrm{Co})_{11} \mathrm{Ti}$ by melt spinning and mechanical alloying. Journal of Magnetism and Magnetic Materials, 2017. 428: p. 194-197 DOI: https://doi.org/10.1016/j.jmmm.2016.12.036.

17. Tozman, P., H. Sepehri-Amin, Y.K. Takahashi, S. Hirosawa, and K. Hono, Intrinsic magnetic properties of $\mathrm{Sm}\left(\mathrm{Fe}_{1-x} \mathrm{Co}_{x}\right)_{11} \mathrm{Ti}$ and $\mathrm{Zr}$-substituted $\mathrm{Sm}_{1-y} \mathrm{Zr}_{y}\left(\mathrm{Fe}_{0.8} \mathrm{Co}_{0.2}\right)_{11.5} \mathrm{Ti}_{0.5}$ compounds with ThMn 12 structure toward the development of permanent magnets. Acta Materialia, 2018. 153: p. 354-363 DOI: https://doi.org/10.1016/j.actamat.2018.05.008. 
18. Saito, T., F. Watanabe, and D. Nishio-Hamane, Magnetic properties of SmFe I2-based $^{2}$ magnets produced by spark plasma sintering method. Journal of Alloys and Compounds, 2019. 773: p. 1018-1022 DOI: https://doi.org/10.1016/j.jallcom.2018.09.297.

19. Neznakhin, D.S., S.V. Andreev, M.A. Semkin, N.V. Selezneva, M.N. Volochaev, A.S. Bolyachkin, N.V. Kudrevatykh, and A.S. Volegov, Structure and magnetic properties of (Sm0.9 $\left.\mathrm{Zr}_{0.1}\right) \mathrm{Fe}_{11}$ Ti alloys with ThMn $n_{12}$-type structure. Journal of Magnetism and Magnetic Materials, 2019. 484: p. 212-217 DOI: https://doi.org/10.1016/j.jmmm.2019.04.030.

20. Dirba, I., H. Sepehri-Amin, T. Ohkubo, and K. Hono, Development of ultra-fine grain sized $\mathrm{SmFe}_{12}$-based powders using hydrogenation disproportionation desorption recombination $\begin{array}{llllll}\text { process. } & \text { Acta } & \text { Materialia, 2019. 165: p. 373-380 DOI: }\end{array}$ https://doi.org/10.1016/j.actamat.2018.11.065.

21. Skomski, R. and J.M.D. Coey, Magnetic anisotropy - How much is enough for a permanent magnet? Scripta Materialia, 2016. 112: p. 3-8 DOI: https://doi.org/10.1016/j.scriptamat.2015.09.021.

22. Hirosawa, S., M. Nishino, and S. Miyashita, Perspectives for high-performance permanent magnets: applications, coercivity, and new materials. Advances in Natural Sciences: Nanoscience and Nanotechnology, 2017. 8(1): p. 013002 DOI: 10.1088/20436254/aa597c.

23. Kawashita, Y., N. Waki, T. Tayu, T. Sugiyama, H. Ono, H. Koyama, H. Kanno, and T. Uchida, Microstructures and magnetic properties of hydrogenation disproportionation desorption recombination-processed $\mathrm{Nd}-\mathrm{Fe}-\mathrm{B}$ materials with different $\mathrm{Nd}$ content of 11.0 
and 12.6 at.\%. Journal of Alloys and Compounds, 2003. 360(1): p. 322-329 DOI: https://doi.org/10.1016/S0925-8388(03)00504-8.

24. Kawashita, Y., N. Waki, T. Tayu, T. Sugiyama, H. Ono, H. Koyama, H. Kanno, and T. Uchida, Magnetic properties of $\mathrm{Nd}-\mathrm{Fe}-\mathrm{B}$ system anisotropic HDDR powder made from segregated master ingots. Journal of Magnetism and Magnetic Materials, 2004. 269(3): p. 293-301 DOI: https://doi.org/10.1016/S0304-8853(03)00595-X.

25. Sepehri-Amin, H., W.F. Li, T. Ohkubo, T. Nishiuchi, S. Hirosawa, and K. Hono, Effect of $\mathrm{Ga}$ addition on the microstructure and magnetic properties of hydrogenationdisproportionation-desorption-recombination processed $\mathrm{Nd}-\mathrm{Fe}-\mathrm{B}$ powder. Acta Materialia, 2010. 58(4): p. 1309-1316 DOI: https://doi.org/10.1016/j.actamat.2009.10.035.

26. Nakayama, R., T. Takeshita, M. Itakura, N. Kuwano, and K. Oki, Microstructures and crystallographic orientation of crystalline grains in anisotropic $\mathrm{Nd}-\mathrm{Fe}-\mathrm{Co}-\mathrm{B}-(\mathrm{Ga}$ or $\mathrm{Zr})$ magnet powders produced by the hydrogenation-decomposition-desorptionrecombination process. Journal of Applied Physics, 1994. 76(1): p. 412-417 DOI: $10.1063 / 1.357091$.

27. Sepehri-Amin, H., T. Ohkubo, T. Nishiuchi, S. Hirosawa, and K. Hono, Coercivity enhancement of hydrogenation-disproportionation-desorption-recombination processed $\mathrm{Nd}-\mathrm{Fe}-\mathrm{B}$ powders by the diffusion of $\mathrm{Nd}-\mathrm{Cu}$ eutectic alloys. Scripta Materialia, 2010. 63(11): p. 1124-1127 DOI: https://doi.org/10.1016/j.scriptamat.2010.08.021.

28. Güth, K., J. Lyubina, B. Gebel, L. Schultz, and O. Gutfleisch, Ultra-fine grained Nd-FeB by high pressure reactive milling and desorption. Journal of Magnetism and Magnetic 
$\begin{array}{lllll}\text { Materials, } & \text { 2012. } & \text { 324(18): } & \text { p. } & \text { 2731-2735 }\end{array}$ https://doi.org/10.1016/j.jmmm.2012.03.059.

29. Gutfleisch, O., B. Gebel, M. Kubis, K.H. Müller, and L. Schultz, Modified HDDR procedures applied to NdFeB alloys. IEEE Transactions on Magnetics, 1999. 35(5): p. 3250-3252 DOI: 10.1109/20.800488.

30. Hütten, A. and G. Thomas, Microstructural parameters of melt-spun $N_{15} F_{77} B_{8}$ ribbons. Ultramicroscopy, 1992. 47(4): p. 447-454 DOI: https://doi.org/10.1016/03043991(92)90176-K.

31. Harland, C.L. and H.A. Davies, Magnetic properties of melt-spun Nd-rich NdFeB alloys with Dy and Ga substitutions. Journal of Alloys and Compounds, 1998. 281(1): p. 37-40 DOI: https://doi.org/10.1016/S0925-8388(98)00767-1.

32. Vincent, J.H. and M.J.P.D. Wyborn, Production of Nd-Fe-B magnets by the rapid solidification processing route. Materials \& Design, 1990. 11(4): p. 207-212 DOI: https://doi.org/10.1016/0261-3069(90)90156-E.

33. Hua, H.C., G.Y. Wang, C.H. Zheng, G.X. Huang, Q.Z. Xu, L.H. Wu, and S.Y. Shi, Microstructure of melt-spun NdFeB magnet. Materials Letters, 1988. 7(1): p. 65-67 DOI: https://doi.org/10.1016/0167-577X(88)90085-7.

34. Ramesh, R., G. Thomas, and B.M. Ma, Magnetization reversal in nucleation controlled magnets. II. Effect of grain size and size distribution on intrinsic coercivity of $\mathrm{Fe}-\mathrm{Nd}$-B magnets. Journal of Applied Physics, 1988. 64(11): p. 6416-6423 DOI: 10.1063/1.342055. 
35. Li, W.F., T. Ohkubo, K. Hono, and M. Sagawa, The origin of coercivity decrease in fine grained $N d-F e-B$ sintered magnets. Journal of Magnetism and Magnetic Materials, 2009. 321(8): p. 1100-1105 DOI: https://doi.org/10.1016/j.jmmm.2008.10.032.

36. Goto, R., M. Matsuura, S. Sugimoto, N. Tezuka, Y. Une, and M. Sagawa, Microstructure evaluation for Dy-free Nd-Fe-B sintered magnets with high coercivity. Journal of Applied Physics, 2012. 111(7): p. 07A739 DOI: 10.1063/1.3680190.

37. Cui, W.B., Y.K. Takahashi, and K. Hono, Microstructure optimization to achieve high coercivity in anisotropic $N d-F e-B$ thin films. Acta Materialia, 2011. 59(20): p. 7768-7775 DOI: https://doi.org/10.1016/j.actamat.2011.09.006.

38. Akdogan, N.G., N.M. Dempsey, D. Givord, A. Manabe, T. Shoji, M. Yano, and A. Kato, Influence of $\mathrm{Nd}$ and $\mathrm{Cu}$ content on the microstructural and magnetic properties of $\mathrm{NdFeB}$ thick films. Journal of Applied Physics, 2014. 115(17): p. 17A722 DOI: $10.1063 / 1.4865462$.

39. Xie, Y., Y. Yang, T. Zhang, Y. Fu, Q. Jiang, S. Ma, Z. Zhong, W. Cui, and Q. Wang, Microstructure evolution and coercivity enhancement in Nd-Fe-B thin films diffusionprocessed by $R$-Al alloys $(R=N d$, Pr). AIP Advances, 2018. 8(5): p. 056202 DOI: $10.1063 / 1.5006110$

40. Khlopkov, K., O. Gutfleisch, D. Eckert, D. Hinz, B. Wall, W. Rodewald, K.H. Müller, and L. Schultz, Local texture in Nd-Fe-B sintered magnets with maximised energy density. Journal of Alloys and Compounds, 2004. 365(1): p. 259-265 DOI: https://doi.org/10.1016/S0925-8388(03)00636-4. 
41. Khlopkov, K., O. Gutfleisch, D. Hinz, K.-H. Müller, and L. Schultz, Evolution of interaction domains in textured fine-grained Nd2Fe14B magnets. Journal of Applied Physics, 2007. 102(2): p. 023912 DOI: 10.1063/1.2751092.

42. Walther, A., K. Khlopkov, O. Gutfleisch, D. Givord, and N.M. Dempsey, Evolution of magnetic and microstructural properties of thick sputtered NdFeB films with processing temperature. Journal of Magnetism and Magnetic Materials, 2007. 316(2): p. 174-176 DOI: https://doi.org/10.1016/j.jmmm.2007.02.047.

43. Gutfleisch, O., K. Khlopkov, A. Teresiak, K. Muller, G. Drazic, C. Mishima, and Y. Honkura, Memory of texture during HDDR Processing of NdFeB. IEEE Transactions on Magnetics, 2003. 39(5): p. 2926-2931 DOI: 10.1109/TMAG.2003.815749.

44. Bollero, A., A. Kirchner, O. Gutfleisch, K. Muller, and L. Schultz, Highly coercive milled and melt-spun $(\mathrm{Pr}, \mathrm{Nd}) \mathrm{FeB}$-type magnets and their hot workability. IEEE Transactions on Magnetics, 2001. 37(4): p. 2483-2485 DOI: 10.1109/20.951210.

45. Kirchner, A., W. Grünberger, O. Gutfleisch, V. Neu, K.H. Müller, and L. Schultz, A comparison of the magnetic properties and deformation behaviour of $\mathrm{Nd}-\mathrm{Fe}-\mathrm{B}$ magnets made from melt-spun, mechanically alloyed and HDDR powders. Journal of Physics D: Applied Physics, 1998. 31(14): p. 1660-1666 DOI: 10.1088/0022-3727/31/14/008.

46. Gutfleisch, O., D. Eckert, R. Schäfer, K.H. Müller, and V. Panchanathan, Magnetization processes in two different types of anisotropic, fully dense NdFeB hydrogenation, disproportionation, desorption, and recombination magnets. Journal of Applied Physics, 2000. 87(9): p. 6119-6121 DOI: 10.1063/1.372628. 
47. Ohashi, K., Y. Tawara, R. Osugi, and M. Shimao, Magnetic properties of Fe-rich rareearth intermetallic compounds with a ThMn $n_{12}$ structure. Journal of Applied Physics, 1988. 64(10): p. 5714-5716 DOI: 10.1063/1.342235.

48. Tatsuki, T., H. Nakamura, S. Sugimoto, M. Okada, and M. Homma, Enhancement of the Magnetic Properties of Sm-Fe and Nd-Fe-N Alloys with ThMn $n_{12}$ Structure by Utilizing HDDR Phenomena. IEEE Translation Journal on Magnetics in Japan, 1993. 8(11): p. 755762 DOI: 10.1109/TJMJ.1993.4565741.

49. Sugimoto, S., T. Shimono, H. Nakamura, T. Kagotani, M. Okada, and M. Homma, Magnetic properties and microstructures of the $\left(\mathrm{SmFe}_{10} \mathrm{~V}_{2}\right)_{1-x^{-}}\left(\mathrm{Sm}_{2} \mathrm{Fe}_{17}\right)_{x}$ cast alloys. Materials Chemistry and Physics, 1995. 42(4): p. 298-301 DOI: https://doi.org/10.1016/0254-0584(96)80018-6.

50. Dirba, I., J. Li, H. Sepehri-Amin, T. Ohkubo, T. Schrefl, and K. Hono, Anisotropic, single-

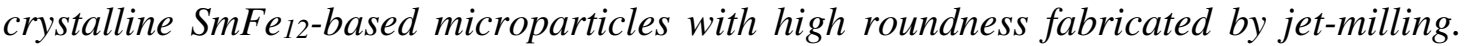
Journal of Alloys and Compounds, 2019. 804: p. 155-162 DOI: https://doi.org/10.1016/j.jallcom.2019.06.365.

51. Gabay, A.M. and G.C. Hadjipanayis, Mechanochemical synthesis of magnetically hard anisotropic $\mathrm{RFe}_{10} \mathrm{Si}_{2}$ powders with $\mathrm{R}$ representing combinations of Sm, Ce and Zr. Journal of Magnetism and Magnetic Materials, 2017. 422: p. 43-48 DOI: https://doi.org/10.1016/j.jmmm.2016.08.064.

52. Singleton, E.W., J. Strzeszewski, G.C. Hadjipanayis, and D.J. Sellmyer, Magnetic and structural properties of melt-spun rare-earth transition-metal intermetallics with $\mathrm{ThMn}_{12}$ structure. Journal of Applied Physics, 1988. 64(10): p. 5717-5719 DOI: 10.1063/1.342236. 
53. Strzeszewski, J., Y.Z. Wang, E.W. Singleton, and G.C. Hadjipanayis, High coercivity in Sm(FeT) $)_{12}$ type magnets. IEEE Transactions on Magnetics, 1989. 25(5): p. 3309-3311 DOI: $10.1109 / 20.42287$.

54. Okada, M., K. Yamagishi, and M. Homma, High Coercivity in Melt-Spun $\operatorname{SmFe}_{10}\left(\mathrm{TiV}_{2}\right.$ Ribbons. Materials Transactions, JIM, 1989. 30(5): p. 374-377 DOI: 10.2320/matertrans 1989.30.374.

55. Sugimoto, S., A. Kojima, M. Okada, and M. Homma, Enhancement of Magnetic Properties of $\operatorname{Sm}(\mathrm{Fe}, \mathrm{Co}, \mathrm{Ti})_{12}$ Melt-Spun Ribbons by Refining Crystallized Grains. Materials Transactions, JIM, 1991. 32(12): p. 1180-1183 DOI: 10.2320/matertrans1989.32.1180.

56. Pinkerton, F.E. and D.J.V. Wingerden, Magnetic hardening of $\mathrm{SmFe}_{10} \mathrm{~V}_{2}$ by melt-spinning. IEEE Transactions on Magnetics, 1989. 25(5): p. 3306-3308 DOI: 10.1109/20.42285.

57. Wang, Y., G.C. Hadjipanayis, A. Kim, N.C. Liu, and D.J. Sellmyer, Magnetic and structural studies in Sm-Fe-Ti magnets. Journal of Applied Physics, 1990. 67(9): p. 49544956 DOI: $10.1063 / 1.344745$

58. Saito, T., H. Miyoshi, and D. Nishio-Hamane, Magnetic properties of Sm-Fe-Ti nanocomposite magnets with a ThMn $n_{12}$ structure. Journal of Alloys and Compounds, 2012. 519: p. 144-148 DOI: https://doi.org/10.1016/j.jallcom.2011.12.156.

59. Shield, J.E., C.P. Li, and D.J. Branagan, Microstructures and phase formation in rapidly solidified Sm-Fe and Sm-Fe-Ti-C alloys. Journal of Magnetism and Magnetic Materials, 1998. 188(3): p. 353-360 DOI: https://doi.org/10.1016/S0304-8853(98)00208-X. 
60. Hadjipanayis, G.C., A.M. Gabay, A.M. Schönhöbel, A. Martín-Cid, J.M. Barandiaran, and D. Niarchos, ThMn ${ }_{12}$-Type Alloys for Permanent Magnets. Engineering, 2019. In Press DOI: https://doi.org/10.1016/j.eng.2018.12.011.

61. Sepehri-Amin, H., Y. Tamazawa, M. Kambayashi, G. Saito, Y.K. Takahashi, D. Ogawa, T. Ohkubo, S. Hirosawa, M. Doi, T. Shima, and K. Hono, Achievement of high coercivity in $\mathrm{Sm}\left(\mathrm{Fe}_{0.8} \mathrm{Co}_{0.2}\right)_{12}$ anisotropic magnetic thin film by boron doping. Acta Materialia, 2020. 194: p. 337-342 DOI: https://doi.org/10.1016/j.actamat.2020.05.026.

62. Gabay, A.M. and G.C. Hadjipanayis, High-coercivity ThMn $n_{12}$-type monocrystalline SmZr-Fe-Co-Ti particles by high-temperature reduction diffusion. Scripta Materialia, 2021. 196: p. 113760 DOI: https://doi.org/10.1016/j.scriptamat.2021.113760.

63. Palanisamy, D., S. Ener, F. Maccari, L. Schäfer, K.P. Skokov, O. Gutfleisch, D. Raabe, and B. Gault, Grain boundary segregation, phase formation, and their influence on the coercivity of rapidly solidified SmFe ${ }_{11}$ Ti hard magnetic alloys. Physical Review Materials, 2020. 4(5): p. 054404 DOI: 10.1103/PhysRevMaterials.4.054404.

64. Skokov, K., A. Grushishev, A. Khokholkov, Y. Pastushenkov, N. Pankratov, T. Ivanova, and S. Nikitin, Magnetic properties of $\mathrm{Gd}_{3} \mathrm{Fe}_{x} \mathrm{Ti}_{3}(x=34,33, \ldots, 24), \mathrm{TbFe}_{11} \mathrm{Ti}$ and $\mathrm{TbFe} \mathrm{H}_{10} \mathrm{Ti}$ single crystals. Journal of Magnetism and Magnetic Materials, 2004. 272-276: p. 374-375 DOI: https://doi.org/10.1016/j.jmmm.2003.11.147.

65. Maccari, F., L. Schäfer, I. Radulov, L.V.B. Diop, S. Ener, E. Bruder, K. Skokov, and O. Gutfleisch, Rapid solidification of $\mathrm{Nd}_{1+X} \mathrm{Fe}_{11}$ Ti compounds: Phase formation and magnetic $\begin{array}{llllll}\text { properties. } & \text { Acta } & \text { Materialia, 2019. 180: p. } & \text { DOI: }\end{array}$ https://doi.org/10.1016/j.actamat.2019.08.057. 
66. Palanisamy, D., D. Raabe, and B. Gault, Elemental segregation to twin boundaries in a MnAl ferromagnetic Heusler alloy. Scripta Materialia, 2018. 155: p. 144-148 DOI: https://doi.org/10.1016/j.scriptamat.2018.06.037.

67. Yanar, C., V. Radmilovic, W.A. Soffa, and J.M.K. Wiezorek, Evolution of microstructure and defect structure in L10-ordered manganese aluminide permanent magnet alloys. Intermetallics, 2001. 9(10): p. 949-954 DOI: https://doi.org/10.1016/S09669795(01)00095-4.

68. Landuyt, J., G. Tendeloo, J.J. Broek, H. Donkersloot, and H. Zijlstra, Defect structure and magnetic properties of MnAl permanent magnet materials. IEEE Transactions on Magnetics, 1978. 14(5): p. 679-681 DOI: 10.1109/TMAG.1978.1059949.

69. Jakubovics, J.P. and T.W. Jolly, The effect of crystal defects on the domain structure of Mn-Al alloys. Physica B+C, 1977. 86-88: p. 1357-1359 DOI: https://doi.org/10.1016/03784363(77)90910-X.

70. Bance, S., F. Bittner, T.G. Woodcock, L. Schultz, and T. Schrefl, Role of twin and antiphase defects in MnAl permanent magnets. Acta Materialia, 2017. 131: p. 48-56 DOI: https://doi.org/10.1016/j.actamat.2017.04.004.

71. Klemmer, T., D. Hoydick, H. Okumura, B. Zhang, and W.A. Soffa, Magnetic hardening and coercivity mechanisms in L10 ordered FePd ferromagnets. Scripta Metallurgica et Materialia, 1995. 33(10): p. 1793-1805 DOI: https://doi.org/10.1016/0956716X(95)00413-P. 
72. Shima, T. and K. Takanashi, Hard Magnetic Films, in Handbook of Magnetism and Advanced Magnetic Materials, H.K.a.S. Parkin, Editor. 2007, John Wiley \& Sons, Ltd. p. $1-19$.

73. Gau, J.S., R.K. Mishra, and T. Graule, Electron Microscopy of Mn-Al-C Magnets. Magnetics, IEEE Transactions on, 1983. 19: p. 2256-2260 DOI: 10.1109/TMAG.1983.1062798.

74. Zhang, B. and W.A. Soffa, Magnetic domains and coercivity in polytwinned ferromagnets. physica status solidi (a), 1992. 131(2): p. 707-725 DOI: 10.1002/pssa.2211310239.

75. Attané, J.P., Y. Samson, A. Marty, D. Halley, and C. Beigné, Domain wall pinning on strain relaxation defects in FePt(001)/Pt thin films. Applied Physics Letters, 2001. 79(6): p. 794-796 DOI: $10.1063 / 1.1390321$.

76. Glijer, P., K. Sin, J.M. Sivertsen, and J.H. Judy, Correlation of structural defects and magnetic properties in CoCrPt/Cr and CoCrTaPt/Cr thin films for ultra high density magnetic recording media. Scripta Metallurgica et Materialia, 1995. 33(10): p. 1585-1592 DOI: https://doi.org/10.1016/0956-716X(95)00403-I.

77. Demczyk, B.G. and D.E. Laughlin, Growth Characteristics of Co-Cr Thin Films for Magnetic Recording. MRS Proceedings, 1988. 119: p. 159 DOI: 10.1557/PROC-119-159.

78. Jia, Y., Y. Wu, S. Zhao, S. Zuo, K.P. Skokov, O. Gutfleisch, C. Jiang, and H. Xu, L1o rareearth-free permanent magnets: The effects of twinning versus dislocations in $\mathrm{Mn}-\mathrm{Al}$ magnets. Physical Review Materials, 2020. 4(9): p. 094402 DOI: 10.1103/PhysRevMaterials.4.094402. 
79. Rodríguez-Carvajal, J., Recent advances in magnetic structure determination by neutron powder diffraction. Physica B: Condensed Matter, 1993. 192(1): p. 55-69 DOI: https://doi.org/10.1016/0921-4526(93)90108-I.

80. Felfer, P.J., T. Alam, S.P. Ringer, and J.M. Cairney, A reproducible method for damagefree site-specific preparation of atom probe tips from interfaces. Microscopy Research and Technique, 2012. 75(4): p. 484-491 DOI: 10.1002/jemt.21081.

81. Makineni, S.K., M. Lenz, P. Kontis, Z. Li, A. Kumar, P.J. Felfer, S. Neumeier, M. Herbig, E. Spiecker, D. Raabe, and B. Gault, Correlative Microscopy—Novel Methods and Their Applications to Explore 3D Chemistry and Structure of Nanoscale Lattice Defects: A Case Study in Superalloys. JOM, 2018. 70(9): p. 1736-1743 DOI: 10.1007/s11837-018-2802-7.

82. Herbig, M., P. Choi, and D. Raabe, Combining structural and chemical information at the nanometer scale by correlative transmission electron microscopy and atom probe tomography. Ultramicroscopy, 2015. 153: p. $32-39$ DOI: https://doi.org/10.1016/j.ultramic.2015.02.003.

83. Quey, R., P.R. Dawson, and F. Barbe, Large-scale 3D random polycrystals for the finite element method: Generation, meshing and remeshing. Computer Methods in Applied Mechanics and Engineering, 2011. 200(17): p. 1729-1745 DOI: https://doi.org/10.1016/j.cma.2011.01.002.

84. Ribes, A. and C. Caremoli. Salomé platform component model for numerical simulation. in 31 st Annual International Computer Software and Applications Conference (COMPSAC 2007). 2007.

85. MeshGems, Distene's MeshGem Software. http://www.meshgems.com/, 2016. 
86. Qiushi, C. and A. Konrad, A review of finite element open boundary techniques for static and quasi-static electromagnetic field problems. IEEE Transactions on Magnetics, 1997. 33(1): p. 663-676 DOI: 10.1109/20.560095.

87. Exl, L., J. Fischbacher, A. Kovacs, H. Oezelt, M. Gusenbauer, and T. Schrefl, Preconditioned nonlinear conjugate gradient method for micromagnetic energy minimization. Computer Physics Communications, 2019. 235: p. 179-186 DOI: https://doi.org/10.1016/j.cpc.2018.09.004.

88. Hunter, J.D., Matplotlib: A 2D Graphics Environment. Computing in Science \& Engineering, 2007. 9(3): p. 90-95 DOI: 10.1109/MCSE.2007.55.

89. Stoner, E.C. and E.P. Wohlfarth, A mechanism of magnetic hysteresis in heterogeneous alloys. Philosophical Transactions of the Royal Society of London. Series A, Mathematical and Physical Sciences, 1948. 240(826): p. 599-642 DOI: doi:10.1098/rsta.1948.0007.

90. Kronmüller, H., K.D. Durst, and M. Sagawa, Analysis of the magnetic hardening mechanism in RE-FeB permanent magnets. Journal of Magnetism and Magnetic Materials, 1988. 74(3): p. 291-302 DOI: https://doi.org/10.1016/0304-8853(88)90202-8.

91. Brown, W.F., Virtues and Weaknesses of the Domain Concept. Reviews of Modern Physics, 1945. 17(1): p. 15-19 DOI: 10.1103/RevModPhys.17.15.

92. Karpenkov, D.Y., K.P. Skokov, M.B. Lyakhova, I.A. Radulov, T. Faske, Y. Skourski, and O. Gutfleisch, Intrinsic magnetic properties of hydrided and non-hydrided Nd5Fe17 single crystals. Journal of Alloys and Compounds, 2018. 741: p. 1012-1020 DOI: https://doi.org/10.1016/j.jallcom.2018.01.239. 
93. Bolyachkin, A.S., D.S. Neznakhin, T.V. Garaeva, A.V. Andreev, and M.I. Bartashevich, Magnetic anisotropy of YFe3 compound. Journal of Magnetism and Magnetic Materials, 2017. 426: p. 740-743 DOI: https://doi.org/10.1016/j.jmmm.2016.10.133.

94. Kuz'min, M.D., K.P. Skokov, I. Radulov, C.A. Schwöbel, S. Foro, W. Donner, M. Werwiński, J. Rusz, E. Delczeg-Czirjak, and O. Gutfleisch, Magnetic anisotropy of La2Co7. Journal of Applied Physics, 2015. 118(5): p. 053905 DOI: 10.1063/1.4927849.

95. Diop, L.V.B., M.D. Kuz'min, Y. Skourski, K.P. Skokov, I.A. Radulov, and O. Gutfleisch, Determination of the crystal field parameters in SmFe 11 Ti. Physical Review B, 2020. 102(6): p. 064423 DOI: 10.1103/PhysRevB.102.064423.

96. Venkateswaran, S.P., N.T. Nuhfer, and M. De Graef, Magnetic domain memory in multiferroic $\mathrm{Ni}_{2} \mathrm{MnGa}$. Acta Materialia, 2007. 55(16): p. 5419-5427 DOI: https://doi.org/10.1016/j.actamat.2007.05.055.

97. Ge, Y., O. Heczko, O. Söderberg, and S.-P. Hannula, Direct optical observation of magnetic domains in Ni-Mn-Ga martensite. Applied Physics Letters, 2006. 89(8): p. 082502 DOI: $10.1063 / 1.2335811$.

98. Lord, D.G., A.P. Holden, and P.J. Grundy, Magnetic force microscopy of Terfenol-D fracture surfaces. Journal of Applied Physics, 1997. 81(8): p. 5728-5730 DOI: 10.1063/1.364650.

99. Dooley, J., M.D. Graef, and M.E. McHenry, Induction mapping of magnetostrictive materials. Journal of Applied Physics, 1998. 83(11): p. 6837-6839 DOI: 10.1063/1.367817. 
100. Coey, J.M.D., Magnetism and Magnetic Materials. 2010, Cambridge: Cambridge University Press.

101. Nespolo, M. and C. Iordache, Twiny: from morphology to twin element and vice versa. Journal of Applied Crystallography, 2013. 46(3): p. 801-803 DOI: doi:10.1107/S0021889813009746.

102. Wirth, S.W., M; Müller, K H; Margarian, A. Determination of anisotropy constants for monoclinic ferromagnetic compounds. in 9. international symposium on magnetic anisotropy and coercivity in rare-earth transition metal alloys and 14. international workshop on rare-earth magnets and their applications. 1996. Sao Paulo (Brazil).

103. Sobh, H.A., S.H. Aly, and S. Yehia, Calculation of magnetization curves and probability distribution for monoclinic and uniaxial systems. Journal of Magnetism and Magnetic Materials, 2013. 331: p. 174-182 DOI: https://doi.org/10.1016/j.jmmm.2012.11.017.

104. Tang, N., X.C. Kou, F.R.d. Boer, K.H.J. Buschow, J.L. Wang, and F. Yang, Magnetocrystalline anisotropy of novel $R_{3}(F e, M)_{29}$ compounds. Journal of Physics: Condensed Matter, 1999. 11(27): p. 5313-5320 DOI: 10.1088/0953-8984/11/27/307.

105. Negri, D., A. Paoluzi, and L. Pareti, Magnetic anisotropy and magnetisation processes in 3:29, 1:12 and 2:17 type Nd:(Fe, Co, Ti) related compounds. Journal of Magnetism and Magnetic Materials, 2004. 269(3): p. 302-310 DOI: https://doi.org/10.1016/S0304$\underline{8853(03) 00618-8 .}$.

106. Sakuma, A., T. Suzuki, T. Furuuchi, T. Shima, and K. Hono, Magnetism of Nd-Fe films as a model of grain boundary phase in $\mathrm{Nd}-\mathrm{Fe}-\mathrm{B}$ permanent magnets. Applied Physics Express, 2015. 9(1): p. 013002 DOI: 10.7567/apex.9.013002. 
107. Schrefl, T., H.F. Schmidts, J. Fidler, and H. Kronmüller, The role of exchange and dipolar coupling at grain boundaries in hard magnetic materials. Journal of Magnetism and Magnetic Materials, 1993. 124(3): p. 251-261 DOI: https://doi.org/10.1016/0304$\underline{8853(93) 90123-\mathrm{J}}$. 